\title{
Notes on nine biological indicators estimable from trawl surveys with an illustrative assessment for North Sea cod
}

\author{
John Cotter ${ }^{1, a}$, Benoit Mesnil ${ }^{2}$, Peter Witthames ${ }^{1}$ and Matt Parker-Humphreys ${ }^{1}$ \\ ${ }^{1}$ Cefas, Lowestoft, NR33 0HT, UK \\ 2 Ifremer, Département EMH, BP 21105, 44311 Nantes, France
}

Received 25 June 2008; Accepted 28 January 2009

\begin{abstract}
This paper reviews a selection of nine indicators for assessing the biological state of a fish population monitored only by using trawl surveys in which catchability is assumed constant from time to time and place to place. The intention is to inform or remind of the range of possibilities and of associated practical and statistical issues. The indicators, grouped according to relationships with abundance, length, age, weight, and reproduction, are documented in a standard format covering estimation, interpretability, sensitivity, considerations for reference points where possible, and an example of their application. Lastly, selected indicators together with year-class curves fitted to abundance indices-at-age are applied to the North Sea cod to demonstrate the feasibility of an assessment based on only one trawl survey. Results support findings of the International Council for the Exploration of the Sea (ICES) working group on the assessment of demersal stocks in the North Sea and Skagerrak.
\end{abstract}

Key words: Biological indicators / Length-based indicators / Age composition / Maturity stage / Weight index / Year-class curves / Ecosystem approach to fisheries management

\section{Introduction}

Indicators are available to measure most biological aspects of the state of a wild marine fish stock, e.g. abundance, rates of mortality, length and age compositions, annual recruitment, growth, bodily condition, and sexual maturity. Such indicators are termed "population indicators" when they apply to a population or stock of one species, the alternative being "community indicators", when they apply to more than one species (Rochet et al. 2005). They are also termed "state" indicators in the "pressure-state-response" (PSR) system for classifying indicators (Garcia and Staples 2000; Jennings 2005). We have used the word "indicator" to include basic measures such as numbers and weights of fish, as well as variables derived from them such as the mortality coefficient and condition index. Monitoring of indicator values offers possibilities for managing fish stocks that are either complementary to, or alternative to time-honoured methods of stock assessment involving the modelling of numbers at different ages (Cotter et al. 2009).

The best method for monitoring biological indicators for a stock is with a fish survey, usually a trawl survey, in which the catchability for each species is reasonably constant from place to place and time to time as a result of careful standardisation

\footnotetext{
${ }^{a}$ Corresponding author:

john.cotter@fishworldscience.com
}

of gear and fishing methods (Anonymous 2004, 2006). The survey should catch small as well as large sizes of the species of interest since the observed values of many indicators are dependent on fish size. A small mesh liner fitted in the codend of the trawl achieves this. The survey should also catch a good selection of the available species in the region since they are important for any kind of ecosystem-based approach to management of the fisheries. Sampling of fish from the landings of commercial fishing vessels is less satisfactory than a trawl survey for monitoring indicators. The time series are likely to be more variable and harder to interpret because of the varying catching powers of commercial vessels (Marchal et al. 2007; Salthaug and Aanes 2003). Also, many small fish and nontarget species would be excluded because they are discarded at sea. Sampling of total catches on commercial fishing vessels using observer surveys avoids the problem of discarding but not that of changing catchabilities.

This paper surveys a small selection of indicators relevant for monitoring significant aspects of the biology of a stock. It is intended as an aide-mémoire or starting point for anyone contemplating management of an annually recruiting fishery using time series of biological indicators estimated from one or more trawl surveys. Readers are expected to adjust the detailed design of each selected indicator to suit the specific circumstances of their stocks and surveys. Fuller reviews of many of the difficult and unresolved issues associated with 
Table 1. Grouped list of biological indicators presented in this paper, some processes affecting them, and the population characteristics that they can indicate when interference from other factors is not excessive.

\begin{tabular}{|c|c|c|c|c|}
\hline $\begin{array}{c}\text { Indicator } \\
\text { group }\end{array}$ & Indicator & Abbreviation & $\begin{array}{c}\text { Main processes } \\
\text { affecting indicator }\end{array}$ & $\begin{array}{c}\begin{array}{c}\text { Population characteristics } \\
\text { indicated }\end{array} \\
\end{array}$ \\
\hline \multirow[t]{2}{*}{$\begin{array}{l}\text { Abundance- } \\
\text { based }\end{array}$} & $\begin{array}{l}\text { Log abundance and } \\
\text { intrinsic population } \\
\text { growth rate }\end{array}$ & $r$ & $\begin{array}{l}\text { Fishing and natural } \\
\text { mortality, reproduction, } \\
\text { migrations }\end{array}$ & $\begin{array}{l}\text { Numerical abundance (as } \\
\text { CPUE) summed over all ages }\end{array}$ \\
\hline & Total mortality & $Z$ & $\begin{array}{l}\text { Fishing and natural } \\
\text { mortality, migrations } \\
\text { with age into or out of } \\
\text { survey area }\end{array}$ & $\begin{array}{l}\text { Rate of dying, } \\
\text { migrations related to age, e.g. } \\
\text { to deep water }\end{array}$ \\
\hline \multirow[t]{2}{*}{$\begin{array}{l}\text { Length- and } \\
\text { age-based }\end{array}$} & $\mathrm{N}$-at-length, N-at-age & $\mathrm{NaL}, \mathrm{NaA}$ & $\begin{array}{l}\text { Recruitment, growth, } \\
\text { fishing and natural } \\
\text { mortality }\end{array}$ & $\begin{array}{l}\text { Length and age frequency } \\
\text { distributions }\end{array}$ \\
\hline & Length statistics & $\begin{array}{l}\text { Lbar, L25, L50, } \\
\text { L75 etc. }\end{array}$ & $\begin{array}{l}\text { Recruitment, growth, } \\
\text { fishing and natural } \\
\text { mortality }\end{array}$ & $\begin{array}{l}\text { Growth, length frequency } \\
\text { distribution, recruitment }\end{array}$ \\
\hline \multirow[t]{2}{*}{ Weight-based } & $\begin{array}{l}\text { Catch weight per unit } \\
\text { effort }\end{array}$ & WPUE & $\begin{array}{l}\text { Fishing, natural } \\
\text { mortality, growth, } \\
\text { feeding }\end{array}$ & $\begin{array}{l}\text { Numerical abundance, age } \\
\text { composition, growth }\end{array}$ \\
\hline & Condition & $C$ & $\begin{array}{l}\text { Feeding, growth, } \\
\text { spawning cycle }\end{array}$ & $\begin{array}{l}\text { Nutritional status of } \\
\text { individuals, reproductive } \\
\text { fitness }\end{array}$ \\
\hline \multirow[t]{3}{*}{ Reproductive } & $\begin{array}{l}\text { Spawning stock in } \\
\text { number }\end{array}$ & $S S N$ & $\begin{array}{l}\text { Maturation, fishing and } \\
\text { natural mortality, } \\
\text { nutrition }\end{array}$ & $\begin{array}{l}\text { Abundance of potentially } \\
\text { breeding fish, sustainability } \\
\text { of the stock }\end{array}$ \\
\hline & Gonadosomatic index & GSI & $\begin{array}{l}\text { Feeding, maturation } \\
\text { cycle }\end{array}$ & $\begin{array}{l}\text { Nutritional status, } \\
\text { reproductive fitness }\end{array}$ \\
\hline & $\begin{array}{l}\text { Length and age at } \\
\text { maturity }\end{array}$ & LaM50, AaM50 & $\begin{array}{l}\text { Maturation, fishing } \\
\text { evolutionary } \\
\text { selection }\end{array}$ & $\begin{array}{l}\text { Size and age of potentially } \\
\text { breeding fish. }\end{array}$ \\
\hline
\end{tabular}

indicators are provided by Rochet and Trenkel (2003) and Jennings (2005), and in several later papers (e.g. Cury and Christensen 2005; Greenstreet and Rogers 2006). Relatively little attention has been given to statistical aspects of sampling for indicators even though they can substantially affect the observed time series. We have therefore included some comments.

We firstly draw attention to general matters relevant to estimation of most biological indicators using trawl surveys. Next, nine indicators that are amenable to monitoring with a trawl survey are presented in a standard format loosely based on that of Halliday and Mohn (2001) for ease of reference. The indicators, grouped by basis, are listed in Table 1 . We retain a heading for "Reference points" even though setting them is usually problematic for biological indicators (Greenstreet and Rogers 2006) so that there is not necessarily much to write. Each indicator is illustrated with an example even though the data may have been collected for another purpose and a firm interpretation of the observed trend is not available. Lastly, we show how a stock might be assessed from a single trawl survey using a selection of biological indicators together with year-class curves (YCC) that estimate total mortality and annual recruitments from the survey abundance indices-at-age (Cotter et al. 2007). The stock and survey chosen are the North Sea cod and the English groundfish survey (EGFS), also known as part of the International Bottom Trawl Survey and termed IBTS3E.

\subsection{General aspects of surveying biological indicators}

Trawl surveys nowadays are typically designed to enclose the domains inhabited by all the stocks of primary commercial interest. However, other species are likely to be relevant to an ecosystem-based approach to management of the fisheries yet may not be so enclosed. Results for indicators on those species could therefore be affected by movements of fish into and out of the surveyed area. Careful consideration is needed for every monitored species of whether catchability is likely to vary with location, time of year, size, age, or other factors. Also important is whether sufficient fish of each species are caught on the survey to provide dependable indicator values (Trenkel and Cotter 2009). These factors may point to a need to modify the design of a survey that is to be adapted from monitoring of abundance indices of a few species to monitoring of a suite of indicators for many.

Values of biological indicators are likely to vary geographically across the surveyed area. The survey may already be stratified to deal with geographic variation of the primary stocks but this will not necessarily be efficient for estimating indicators on other stocks. Alternative post-survey stratifications, spatial modelling using Kriging (e.g. Cressie 1993), and spatial indicators (Woillez et al. 2009) are possible ways for dealing with spatial variability. Another effect of geographic 
variation is that statistical estimation of summarising statistics for an indicator, e.g. a mean, regression, or quantiles, when applied across several fishing stations, is complicated by the aggregation of fish in certain localities, perhaps differently at different times of year. Estimates will depend on whether averages are "over fish" without regard to the numbers caught at each station, or whether averages are first formed for each station and then themselves averaged "over stations". The former relates more to population size, the latter to geographic variation (Cotter 2009b). The variability and sometimes the trends observed in the indicator series can be affected. A comparison of the two ways of calculating summarising statistics is shown for fish length (Fig. 4).

Other statistical aspects arise. The monitoring of compliance with reference points, assuming that agreeable values can be found, is part of the business of statistical quality control. Mesnil and Petitgas (2009) discuss methods applicable in a fish survey context. Reference points might also be set as arbitrary target values negotatied by interested parties, or as trend directions (Jennings and Dulvy 2005). When monitoring many indicators, the different trend lines can soon become confusing. Various techniques exist for putting together the results of multiple biological (Petitgas 2009); Trenkel et al. 2007) or spatial (Petigas and Poulard 2009) indicators, or a multivariate nonparametric test may be applied to assess monotonic trends in parallel time series of either type of indicator (Cotter 2009a).

\section{Indicators}

\subsection{Abundance-based indicators}

Most trawl surveys routinely estimate abundance indices as catch per unit of effort (CPUE), e.g. numbers per hour or per unit of distance towed, usually by length or age classes. The two following abundance-based indicators may also be valuable when assessing abundance and population dynamics, particularly for non-target species.

\subsubsection{Log abundance and intrinsic population growth rate $(r)$}

Lotka's intrinsic population growth rate, $r$, is the gradient of $\log$ total abundance, $\log N$, over time. Thus $r$ summarises proportional changes in the numerical abundance of all age groups combined. A justification for using $r$ rather than a slope fitted to untransformed abundance indices is that abundance tends to be highly variable from year to year, $\log$ (abundance) less variable and $r$, derived from a trend line fitted to a time series of log abundance indices, less variable again. We can therefore hope that $r$ will reveal the underlying trend in abundance most clearly. Lotka's $r$ was suggested for fish populations by Horst (1977) and further developed as an indicator by Quinn and Szarzi (1993), see also Kot (2001) and Caswell (2001); $r$ is particularly valuable when length and age compositions are unavailable for the stock

\section{Estimation}

The basic model for $r$ is $N_{t}=N_{t-1} \exp (r)$. An estimate of $r$ can therefore be obtained from a least squares fit of $\log N_{t}=\beta_{0}+r t$. It will depend on the time-window chosen for the fit since the linear slope measured by $r$ is merely an average of fluctuations over time. Alternatively, a smoother can be fitted, e.g. a moving average or spline fit (Wood 2006), and the slope estimated for a given time interval from the measured difference in the smoothed values per unit of time.

\section{Interpretability}

The expected effect of fishing is to decrease both log abundance and $r$, although many other factors might have the same effect. Interpretation of $r$ therefore benefits from knowledge of fishing effort, annual recruitments, and consideration of the biological significance of the associated $\log N ; r$ may be related to life history traits of a species (Jennings et al. 1998). Anderson et al. (2008) found evidence for variability of fished populations caused by unstable population dynamics linked with $r$. Gedamke et al. (2007) and Chen and Yuan (2006) investigated $r$ in relation to elasmobranchs.

\section{Sensitivity}

Since $r$ is a measure for all ages combined it is likely to be affected substantially by large recruitment pulses in the stock, particularly if numbers of adults are low. This variability will inevitably delay confident conclusions about the underlying trends in stock abundance and the effects of fishing on them unless other indicators - such as length and age compositions - are brought to bear as well.

\section{Reference points}

A long term average $r=0$ implies that the population has some kind of stability over time. The importance of this, or of some positive value, depends on whether the population is currently showing low or high abundance. For many stocks, the value of $r$ is disturbed by high levels of variability due to annual recruitment. These considerations imply that setting a reference point for $r$ may not be helpful, though there may be circumstances when, say, a doubling of population size $(r=$ 0.69 ) is an agreeable, though arbitrary, objective for the trend line over a fixed period of years starting from a known, low level of abundance.

\section{Example}

Abundance indices (CPUE) for all ages of 3 species caught on the English groundfish survey (EGFS) of the North Sea between 1977 and 2007 are shown transformed to natural logarithms (Fig. 1). A Granton trawl was used by the EGFS until 1991, then a big vertical opening bottom trawl (GOV) trawl and the towing time were changed at the same time from 60 to 30 minutes. Intercalibration factors estimated by Cotter (2001, Table 2) were applied from 1992 to make all CPUE comparable. None of the time series shows a clear linear slope, so moving averages for 5-year periods were fitted (with MS Excel) to indicate smoothed, underlying trends. The gradients, in this 


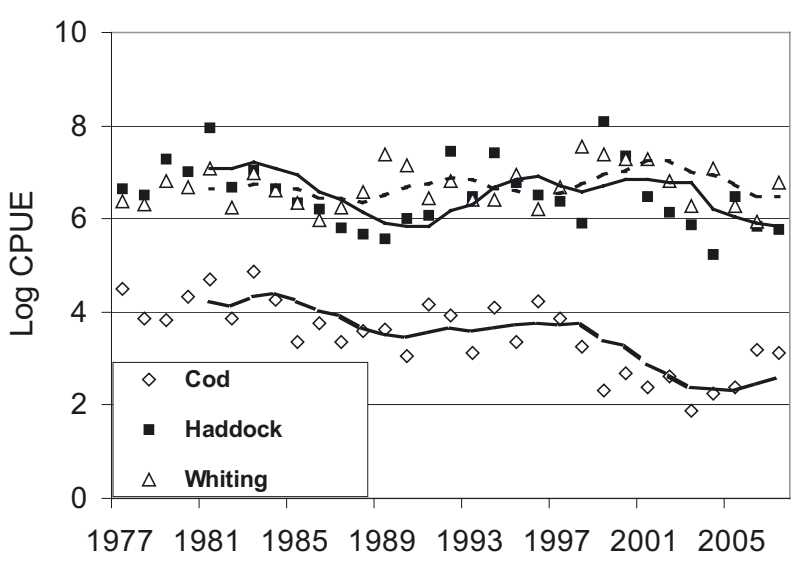

Fig. 1. Examples of log abundance indices and intrinsic population growth rate, $r$, for 3 fish species caught by the English groundfish survey of the North Sea, 1977-2007, corrected for a change to a GOV trawl in 1992. Log CPUE indices (numbers $\mathrm{h}^{-1}$ ) are for all ages combined. Trend lines are 5-year moving averages. Gradients estimate $r$. Whiting: ....; Cod: - - - - ; Haddock: __. Data supplied by Cefas, Lowestoft, UK.

case changing over time, estimate $r$. It can be seen that cod gradually declined relative to haddock and whiting since 1981 . In the last 3 or 4 years of the series, $r$ for cod appears to be increasing, and $r$ for haddock and whiting decreasing. Data were supplied by Cefas Lowestoft, UK.

\subsubsection{Total mortality $(Z)$}

The coefficient or rate of total mortality, $Z$, is the sum of fishing and natural mortalities: $Z=F+M$. $Z$ derives from the exponential model of mortality in population dynamics, i.e. from $\mathrm{d} N / \mathrm{d} t=-Z N$ where $N$ is abundance of a year class, $t$ is time, and $Z$ is conventionally regarded as positive.

\section{Estimation}

The differential equation above solves to $N_{t}=$ $N_{0} \exp (-Z t)$ (Quinn and Deriso 1999) from which

(i) $\log N_{t}=\log N_{0}-Z t$, or

(ii) $Z=-\log \left(N_{t} / N_{t-1}\right)$.

$Z$ may therefore be estimated by fitting linear regressions to $\log$ abundance indices by year-class over age, Equation (i) above (Cotter et al. 2007; Sinclair 2001). Removal of the youngest, and possibly the oldest ages may be necessary to obtain a satisfactory linear fit. Alternatively, $Z$ may be estimated separately for each (age, year) to (age +1 , year +1$)$ using equation (ii) above (Beare et al. 2002; Sinclair 2001), and averaged over consecutive ages.

\section{Interpretability}

In addition to measuring the rate of mortality, $Z$ is also affected by loss or gain of fish from a survey area by other means, usually the result of a net migration occurring in relation to age, e.g. when old fish prefer to live in deeper water. Consistent annual migrations out and back, e.g. for feeding and reproduction, probably will not bias $Z$ estimated from a consistently timed annual survey, though year-to-year variance may be increased. Different $Z$ over different age ranges could be caused by less than full selectivity of the survey gear for some ages. Interpretation of $Z$ requires that $M$ is assumed to be relatively small and constant if, as is usually the case, $M$ is not known accurately (Hewitt and Hoenig 2005; Vetter 1988).

\section{Sensitivity}

Changes in $Z$ over time are only likely to be discernible from surveys when commercial fishing effort changes substantially, but changes in $Z$ regionally resulting from net migration from one region to another as the fish grow older can be readily detected, e.g. for plaice in the southern North Sea (Cotter et al. 2007).

\section{Reference points}

Aiming for a low value of $Z$ should help a stock to recover from heavy fishing if agreeable with the fishing industry who, ultimately, control $F$.

\section{Example}

Abundance indices (CPUE) for plaice caught on the RV Isis beam trawl survey operated by IMARES in the North Sea between 1985 and 2002 are shown transformed to natural logarithms (Fig. 2). Also shown are least squares regression lines whose slopes estimate $-Z$. The fitting procedure used was the "year class curves" (YCC) program written in R (Cotter et al. 2007). Here, the lines are all linear with a common $Z=1.096$. The lack of a clear change in slope over the different ages and year classes suggests that exploitation rates were reasonably constant over the period surveyed, 1985 to 2002. The lack of a consistent pattern of curvature around the fitted lines suggests that the selectivity of the survey trawl did not vary greatly with size. Two other beam trawl surveys (not illustrated) by IMARES gave $Z=0.525$, and $Z=1.572$ which, because of the locations of the survey domains relative to the European shoreline, supported earlier reports of an offshore migration with age (Cotter et al. 2007). The data were supplied by IMARES, IJmuiden, NL.

\subsection{Size- and age-based indicators}

Most trawl surveys routinely estimate length and age frequencies or 'compositions' for commercial species. They may either be examined as they are, or summarised using moments such as the mean, or quantiles. Several considerations common to both methods are presented below. Additional comments specifically for summarising statistics are given.

\subsubsection{Numbers-at-length, numbers-at-age ( $\mathrm{NaL}, \mathrm{NaA})$}

$N a L$ and $N a A$ refer to numbers-at-length and numbers-atage, respectively. They can reveal recruitment, relative numerical strengths of different year classes, and growth in bodily size when monitored over time. 


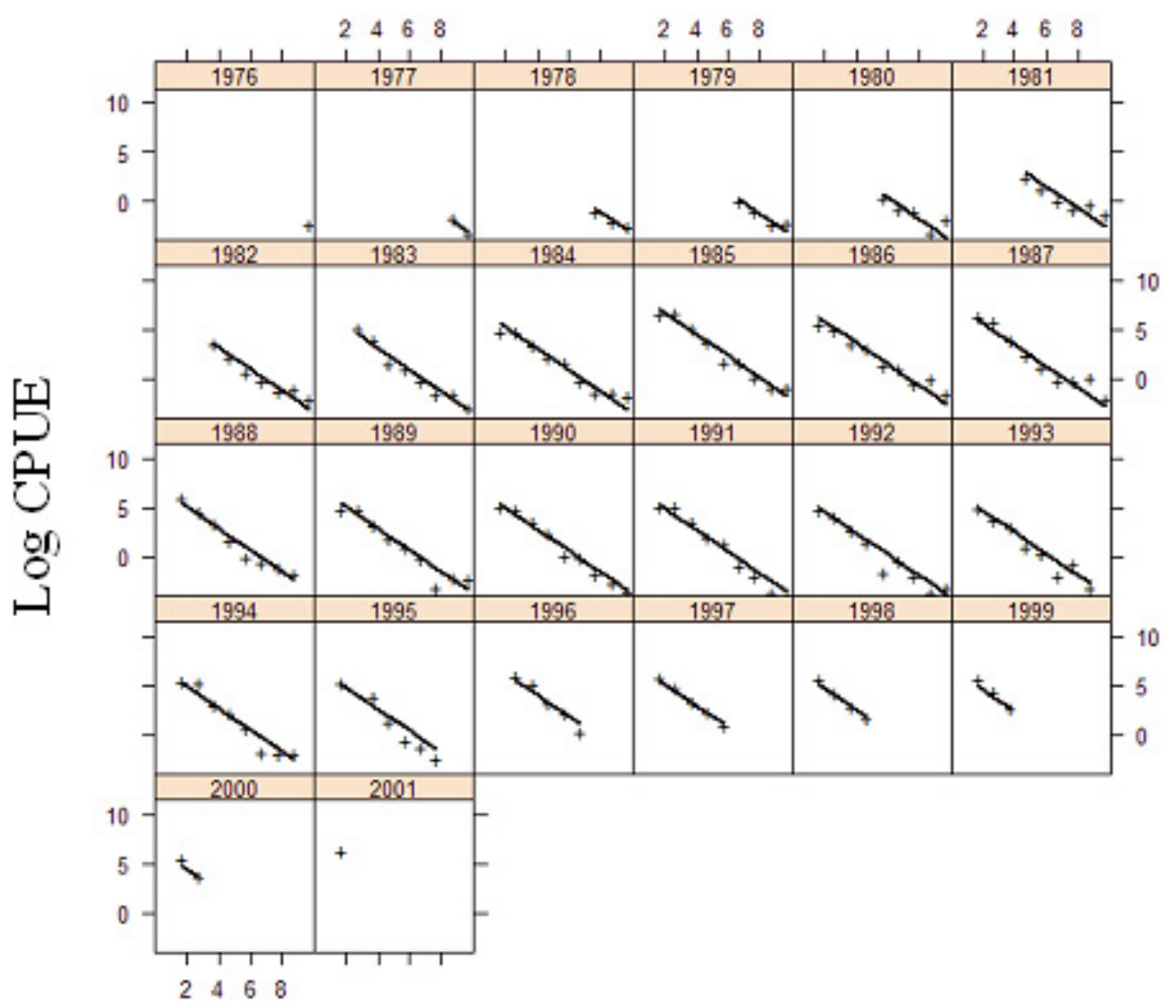

\section{Age}

Fig. 2. Example of the total mortality coefficient, Z, for plaice caught by the RV Isis North Sea beam trawl survey, 1985-2002: observed log CPUE indices (numbers $\mathrm{h}^{-1}$ ) were fitted by least squares with: Log CPUE $\sim$ Yclass + Fleet/Age -1 . The constant gradients estimate Z; panel strips show year class. Graphic output from YCC program (Cotter et al. 2007). Data supplied by IMARES, IJmuiden, The Netherlands.

\section{Estimation}

The bodily extremities used to measure each species should be standardised (Beckett 1983) so that there is no creeping of length measurements across national surveys or years. The size selectivity of the survey trawl will obviously affect the observed length and age compositions, as will variability of the period when young fish settle to the bottom and become vulnerable to a demersal trawl, and the escape of large, fastswimming individuals in front of the trawl. Additionally, different fishing stations are often associated with different sizes of fish, and different geographic patterns of size compositions occur for many species.

When estimating age or length compositions, stations are equally weighted if the histogram obtained at each station is re-scaled to integrate to unity in all cases, then averaged over stations in the survey area, or within the appropriate stratum. On the other hand, fish are equally weighted if the histograms at each station are not re-scaled to unity before adding them across the survey. The example in haddock (length statistics) shows how the different approaches can affect observed time series.

An age-length key (ALK) is often used to estimate $\mathrm{NaA}$ when otoliths or scales are collected for age reading from length-stratified sub-samples of survey catches. An ALK drawn up for each station's catch has the desirable property of being independent from all others (Cotter 1998) thereby allowing $\mathrm{NaA}$ at the station to be considered as a property of that point alone, and to be treated as independent observations for summarising statistics, and spatial models. A regionalised, multi-station ALK on the other hand is based on a larger sample size but imposes a spatial correlation on the $\mathrm{NaA}$ estimated for each station within the region because of shared sampling and ageing errors. A special case of bias arises when ALKs drawn up for one time period are applied to another. This affects estimates of relative year class abundances (Westrheim and Ricker 1978).

\section{Interpretability}

In general, high fishing intensity reduces the relative abundance of large fish, compared to small because: (a) large individuals are mostly older and therefore have had more exposure to fishing gear; (b) commercial trawlers tend to catch large fish more effectively than small; and (c) because large fish are often targeted by the choice of fishing gear and grounds. A stock lacking large or old fish is likely to be over-fished and under-productive economically. Furthermore, the fishery will have difficulty sustaining itself in years when recruitment is poor. However, lack of large fish can also occur due to predation or disease for example (Shin et al. 2005) or just because of poor year classes. Increasing proportions of large or old fish 
in the long term imply better survival with age and a recovery of the stock, whether from reduced fishing or other influences. Knowledge of the abundances of predator-, and prey-species for the species in question may assist interpretation of trends in NaL. A few of the many references relevant to interpretation of fish length are by Ault et al. (2005), Kvamme and Froysa (2004), Deriso and Parma (1988), Piet and Jennings (2006), Jennings et al. (1999), Rochet and Trenkel (2003), Shin and Cury (2004), and (Shin et al. 2005). Lbar for mixtures of species has been shown to increase in communities when fishing pressure is halted (Babcock et al. 1999) and to decrease when fishing pressures are high (Haedrich and Barnes 1997; Jennings et al. 1999).

Mathematically inclined readers are referred to "magic moments", a statistical system for combining $\mathrm{NaL}$, and $\mathrm{NaA}$ so as to simulate stock size, structure, biomass, size selection, maturity, and other features (Pope 2003). Other welldeveloped size-based models are available (Pope et al. 2006; Shin and Cury 2004). They appear to offer considerable assistance for the interpretation of changing size compositions of fish stocks.

\section{Sensitivity}

In general, length and age compositions of a stock change rapidly in response to initial fishing pressure (Jennings 2007), then numbers of older, larger fish remain low. Both indices are affected by pulses of recruitment, or by changing predator populations (Shin et al. 2005), and these factors may be more influential than slight changes of fishing effort.

\section{Reference points}

A sustainable stock should have a reasonable proportion of larger or older individuals capable of breeding (Marteinsdottir and Thorarinsson 1998; Scott et al. 2006) though it is seldom possible to be precise about what is "reasonable". Protection of size or age classes representative of the youngest spawners may not be sufficient if young spawners tend not to be successful at breeding, or if the stock is poorly nourished such that individuals may not breed even though they have reached an age when they could. These considerations suggest that useful length-based reference points might be definable in terms of the proportions of large fish, as has been recommended as a community indicator for fish of all species caught by trawl surveys in the North Sea by ICES (Anonymous 2007a).

\section{Example}

Contrasting length frequency distributions for sole and plaice, one from fish caught in 1993, the other from those caught in 2001, are shown (Fig. 3). The fish were caught by a beam trawl survey off the SW coast of England using the FV Carhelmar equipped with twin 4-metre beam trawls. Data for sole were unsexed, those for plaice were sexed. These $\mathrm{NaL}$ were computed as average CPUE-at-length over stations. Comparisons across the 8-year interval suggest that the sole stock increased in abundance over the period. The youngest sole appear to have been absent from both surveys. The plaice stock increased in abundance in the medium size classes but large females became somewhat less frequent. Recruitment of juvenile plaice was not evident in 1993 but clearly was in 2001. Data were supplied by Cefas Lowestoft, UK.

\subsubsection{Length statistics ( $L b a r, L 25, L 50, L 75$, etc.)}

The following notes specifically on summarising statistics, such as the mean (Lbar) or percentiles (L25, etc.), are additional to the general comments about length frequency distributions.

\section{Estimation}

Lbar is sensitive to extreme values and the number of modes occurring in the length frequency data, possibly resulting in high year-to-year variation. Also, estimation of Lbar with omission of fish shorter than a given length, e.g. the length best separating 0 and 1 -groups, or the minimum landing size (MLS), is likely to improve its precision considerably when annual recruitments are very variable. However, a truncated mean will not necessarily indicate a clearer trend than an untruncated quantile. Estimation of length statistics over fish or over stations can give different results as is illustrated in the example below.

\section{Interpretability}

The $L 25, L 50$, and $L 75$ percentiles characterise the smaller, middle sized, and older fish, respectively, and are therefore expected to respond differently to recruitment pulses, growth factors, and to changes in abundance and spawning stock biomass. Parallel trends for the different percentiles may, nevertheless, be observed. In that case, percentiles further into the tales of the distribution are worth examining, e.g. L05, L95.

\section{Sensitivity}

Lbar in the population is most influenced by the smallest, youngest year classes because they are usually the most numerous. Consequently, time series for Lbar are likely to be noisy if recruitments are highly variable from year to year and, therefore, poorly sensitive to the effects of commercial fishing or factors affecting growth rates. L25 is affected by the number and size of young fish; thus low recruitment of young, small fish would be expected to cause $L 25$ to increase in the same year, and vice versa. L50 would be expected to respond in a similar way to Lbar though possibly with less background noise brought about by outlying values when sample sizes are small. Fish longer than $L 75$ are likely to belong to several age classes. Because of size-selectivity, $L 75$ can be expected to respond quickly to the onset of commercial trawling but slowly to a reduction of trawling pressures because several year classes would need to age and grow in size.

\section{Reference points}

Some options for reference points are:

- Length at $50 \%$ maturity. 

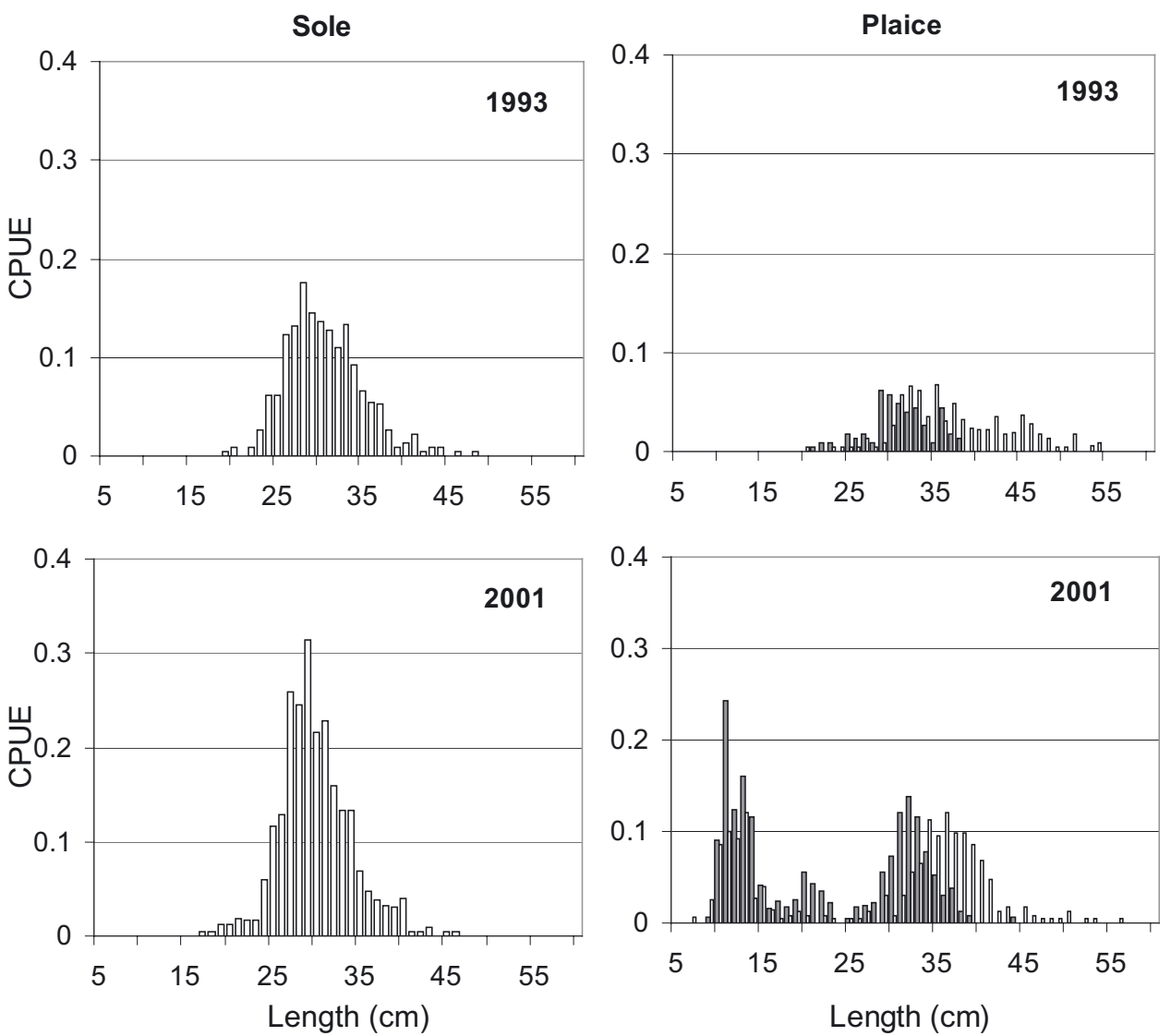

Fig. 3. Contrasting examples of numbers-at-length, $N a L$, estimated as mean CPUEs (numbers $\mathrm{h}^{-1}$ ) over stations for sole and plaice caught by the English south western beam trawl survey in 1993 and 2001. Sole were unsexed. Plaice: males - dark, females - white bars. Data supplied by Cefas.

- Lengths associated with biological events such as migrations.

- Lengths associated with the fishery, e.g. length at $50 \%$ selectivity, or MLS.

- Historic values when the stock was deemed to be at a satisfactory level.

\section{Example}

L05, L50, L95, and Lbar for haddock caught by the English groundfish survey of the North Sea between 1977 and 2007 are shown (Figs. 4a,b); Those in panel 4a were calculated over fish, while those in panel $4 \mathrm{~b}$ were calculated with the same data over stations. The manner of estimation is seen to significantly affect the forms of the time series. In Figure $4 a$, $L 05$ and $L 95$ are widely separated because they relate to large annual samples sizes, between 11000 and 227000 fish. For the same reason, these two quantiles were quite steady until 1999 , particularly that for the L05 relating to the more abundant small length classes. Examination of annual histograms (not shown) showed that the sharp fluctuations after 1999 were caused by varying degrees of bimodality in the length frequency histograms reflecting large year-to-year differences in recruitment. L50 and Lbar show mutually similar patterns (Fig. 4a) but Lbar was higher than $L 50$ generally during years when bimodality was marked. Bimodalities also explain the tendency to more variability in the $L 50$ and Lbar than the $L 05$ and $L 95$. With a consistently monomodal frequency distribution the reverse situation might be expected because relatively few fish are available for estimating quantiles in the tails of the length frequency distribution.

In Figure 4b, the illustrated quantiles represent the averages of quantiles at stations. Hence $L 05$ over stations was generally higher than $L 05$ over fish because not all stations had many young recruits present. It was also somewhat more variable than the $L 05$ over fish because, at each station, sample sizes were small compared to the total number caught over the whole survey. The $L 95$ was less clearly affected by being calculated over stations rather than over fish implying that the larger length classes tended to be present whenever haddock were found at a station. The $L 50$ and Lbar followed each other more closely than when calculated over fish apparently because a bimodal length frequency histogram was not found at every station, this, in turn, being because large numbers of recruits were not found at every station. In this case, L50 or Lbar over stations offered a less variable series for monitoring trends than the same statistics over fish. In conclusion, length statistics calculated over fish and over means can be instructive about different aspects of a stock. Data were supplied by Cefas, Lowestoft, UK. 

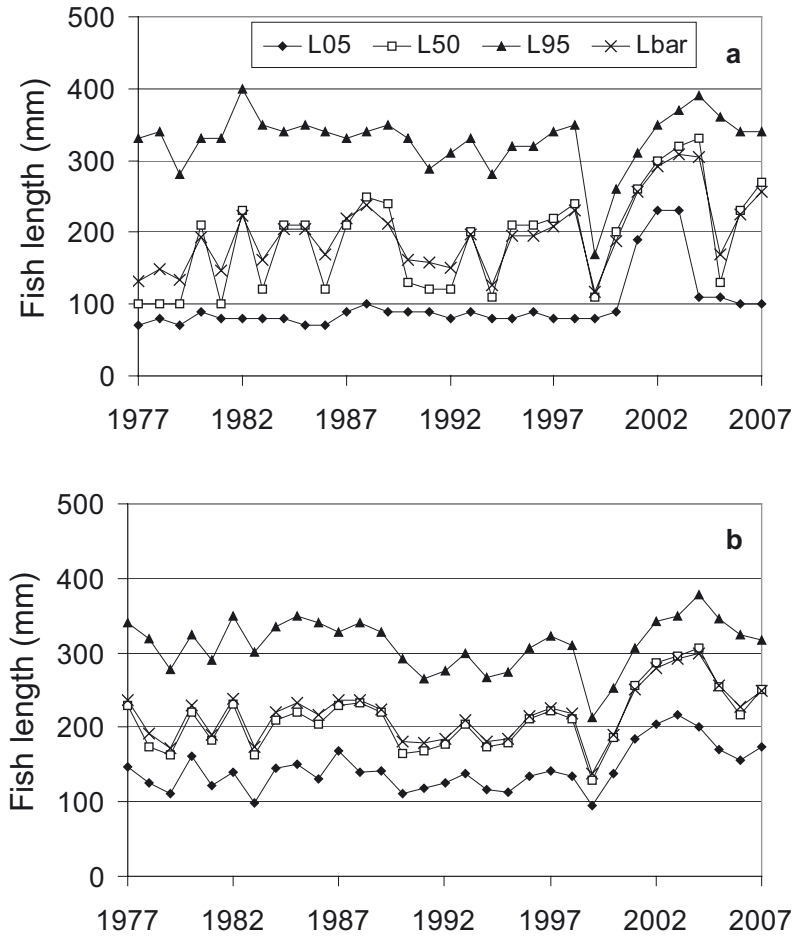

Fig. 4. Example of length-based indicators: length quantiles, $L 05$, $L 50$, and $L 95$, and mean length, Lbar for haddock caught by the EGFS demersal trawl survey of the North Sea, 1977-2007. (a) computed "over fish"; (b) computed "over stations" (Cotter 2009b). Data supplied by Cefas.

\subsection{Weight-based indicators}

Many surveys routinely weigh catches by species. Alternatively, weights may be estimated from lengths for each species using the allometric formula: $W=\sum_{l} n_{l} a l^{b}$ where $l$ is length class, $n_{l}$ is the numbers caught during the entire survey in that length class, and $a$ and $b$ are constants for the species, the first being a scaling factor for units, the second being a factor relating to change of shape with increasing size. The weights of a species caught can serve as an indicator of the strength of the stock that is complementary to abundance-based indicators. Weights can also indicate feeding conditions and maturation of the gonads ready for spawning. Two weight-based indicators are discussed below.

\subsubsection{Catch weight per station (WPUE)}

WPUE is the total weight of one (or more) species caught per station on a survey standardised per unit of effort, either trawling hours or distance towed. The latter is likely to produce better standardisation of catches for ground-dwelling species such as certain flatfish.

\section{Estimation}

Weighing catches on board a survey vessel requires a motion-compensated balance. Common practice is to do this for whole catches of a species rather than for individual fish.
Thus all results pertain to stations and will not necessarily be directly comparable with say, length frequencies, measured over fish. The season of the survey should be kept constant because WPUE might be affected by seasonal changes in availability of food, and by enlargement of gonads for breeding. Previous remarks on factors affecting length frequency distributions are of course also relevant to weight-based indicators.

When weights are estimated allometrically, $a$ and $b$ must first be estimated by regressing $\log \left(W_{l} / n_{l}\right)$ against $\log l$ using samples of weighed and measured fish. The estimates of $a$ and $b$ should be checked at intervals. One would expect them to be constant for a species which does not display varying shapes or gravimetric densities. However, historic estimates may be based on survey catches from restricted localities or time periods where atypical values were observed, perhaps due to the prevailing condition factor. Perpetuating use of these estimates then maintains an unknown bias over time. Repeated sampling of fish for length and weight would help to generalise the estimates of $a$ and $b$ and improve precision. Alternatively, possibly, real variations in shape and density would be discovered. A simpler approach is to use a relative weight index obtained by assuming that $b=3$, implying no change of shape with size; i.e. $W \propto \sum_{l} n_{l} l^{3}$. The assumption may not be satisfactory for all species (Anonymous 2003, Sect. 4.3.1.1).

\section{Interpretability}

WPUE can be expected to vary in response to fishing and other factors that affect abundance-based indicators, for which see comments above. Interpretations of WPUE series should also consider length compositions of the stock. Condition of the fish (weight/length) may also be important for interpreting WPUE but can obviously only be considered if fish weights were measured directly, rather than themselves being estimated from lengths. Calculations of WPUE might be designed to omit fish shorter than the minimum landing size (MLS) for the fishery so that WPUE becomes directly relevant to the legal yield of the fishery, and possibly serviceable as guidance for a harvest control rule (Apostolaki and Hillary 2009). WPUE can be transformed to a mean weight of individual fish. This would be akin to a condition factor (see $C$ below) but without allowing for body length.

\section{Sensitivity}

A significant merit of WPUE is that it is less influenced by varying recruitment from year to year than raw length indices such as Lbar because young fish, although very numerous, are very small, so that their abundance and weight tend to cancel in the overall index. This means that time series for WPUE tend to display less noise than those for abundance indices. WPUE is expected to be influenced by changing abundance, size, and average condition of individuals. Migrational behaviour may also be relevant.

\section{Reference points}

A possibility is to use historical estimates of WPUE when the stock was considered to display a satisfactory age composition, i.e. one having sufficient mature age groups present to 


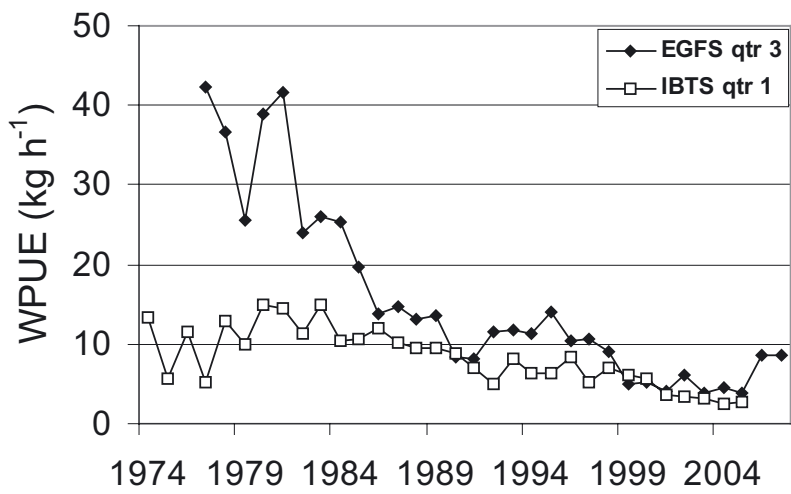

Fig. 5. Example of weight per unit of effort indices, WPUE for North Sea cod. Open squares: WPUE computed allometrically for the International bottom trawl survey, quarter 1, 1974-2005, in the cod standard area of 138 ICES rectangles. Data supplied by ICES Secretariat. Solid diamonds: WPUE $\left(\mathrm{kg} \mathrm{h}^{-1}\right)$ caught by the English groundfish survey, quarter 3, 1977-2007, corrected for a change to a GOV trawl in 1992. Data supplied by Cefas.

provide resilience to occasional poor recruitment or temporary, heavy fishing pressure.

\section{Example}

Weight indices for North Sea cod computed allometrically, and as weighed on deck of the survey vessel are shown in Figure 5. The allometric estimates were prepared from numbers-at-length caught by the quarter 1 International Bottom Trawl Survey (IBTS, Heessen 1997) from 1974 to 2005. Catch-at-length data were transformed using $W \propto \sum_{l} n_{l} l^{3}$ and average catch weight per fishing station per ICES rectangle was estimated as the mean over fish for all catches taken within the rectangle, usually a small number arising from the different national surveys fishing in the locality. These means were averaged over all 138 rectangles in the standard area used to estimate the abundance index for cod to estimate an index of WPUE. The measured catch weights were obtained from the English groundfish survey (EGFS) with an intercalibration factor of 0.61 applied to allow for the changed trawl from 1992 onwards (Cotter 2001).

The EGFS results showed a clear downward trend in WPUE from the 1970s. The IBTS results showed a shallower downward slope starting from the early 1980s. From the mid 1980s, the two independent estimates were in reasonable agreement about the rate of a continuing declining in the catchable weight of cod in the North Sea. This is consistent with the well known decline in the North Sea cod stock in recent years and implies that WPUE serves as a highly relevant indicator in this case. Variable results for the IBTS in the 1970s may possibly have been due to inconsistent survey practices in the early days of the IBTS when the focus was on herring recruitment. However, no attempt has been made here to remove inconsistencies at any time in the series (see Heessen et al. 1997, for details). Variable results for the EGFS in the 1970s may have arisen from the practice then of making replicate tows at around 50 to 60 stations, rather than single tows at approximately 80 stations. Possibly, the replicate tows were motivated by high catches of cod. IBTS data were supplied by the ICES Secretariat, and EGFS data by Cefas.

\subsubsection{Condition (C)}

Condition refers to average body weight for a given body size. It comes from the allometric growth equation, $W=C L^{b}$ and is often normalised as Fulton's condition index (Anderson, R.O. and Neumann 1996), $W / k L^{3}$, where $k$ is chosen for appropriate scaling. $C$ can indicate nutritional status and reproductive fitness of individuals.

\section{Estimation}

A regression of $\log$ (weight per individual at length $l$ ) on $\log l$ will allow estimation of $\log C$ as the intercept and $b$ as the slope. In many studies, $b$ is standardised at 3 , as for the Fulton index, implying growth without change of shape. However for some species, $b$ is not exactly 3.0 with the result that an unwanted relationship between $C$ and length is introduced. There are other subtle statistical issues surrounding condition indices that can bias comparisons (Anonymous 2003; Bolger and Connolly 1989; Cone 1989; Cone et al. 1990; García-Berthou and Moreno-Amich 1993).

The regression referred to above is a type of mean, so the statistical issues already mentioned concerning estimation over fish or over stations are pertinent here as well. In particular, standard errors for $a$ and $b$ estimated from a regression are likely to over-estimate confidence in the result if all fish caught on a trawl survey are treated as being independently and randomly sampled from the stock.

On many surveys, weights of individual fish are only measured for a length-stratified sub-sample of those measured from the catches. This could be an advantage for estimating a weight-length model because observations are evenly spread over length. Ideally, such weight sub-sampling will be carried out at every station where the species is caught so as to spread the sampling effort evenly geographically.

\section{Interpretability}

$C$ varies with season due to annual cycles of feeding and reproduction. Interpretation of trends therefore seems to require that surveys are always scheduled at the same point in the annual biological cycle. On the other hand, García-Berthou and Moreno-Amich (1993) proposed a multivariate analysis of total weight (and gonadal weight) with length as a covariate. They state that seasonal and other variation could then be described by the model, rendering the use of condition (and gonadosomatic) indices unnecessary.

Low condition implies too much competition for available food. This, in turn, implies that some mature individuals may not mature reproductively for the coming spawning season, or that their fecundity may be reduced by follicular atresia (Kennedy et al. 2007; Kennedy et al. 2008; Thoresen et al. 2006). Low condition can also increase the age of first maturity, increase natural mortality of post spawning individuals, and increase the incidence of skipped spawning (Rideout and Rose 2006). Condition varies in males and females according 

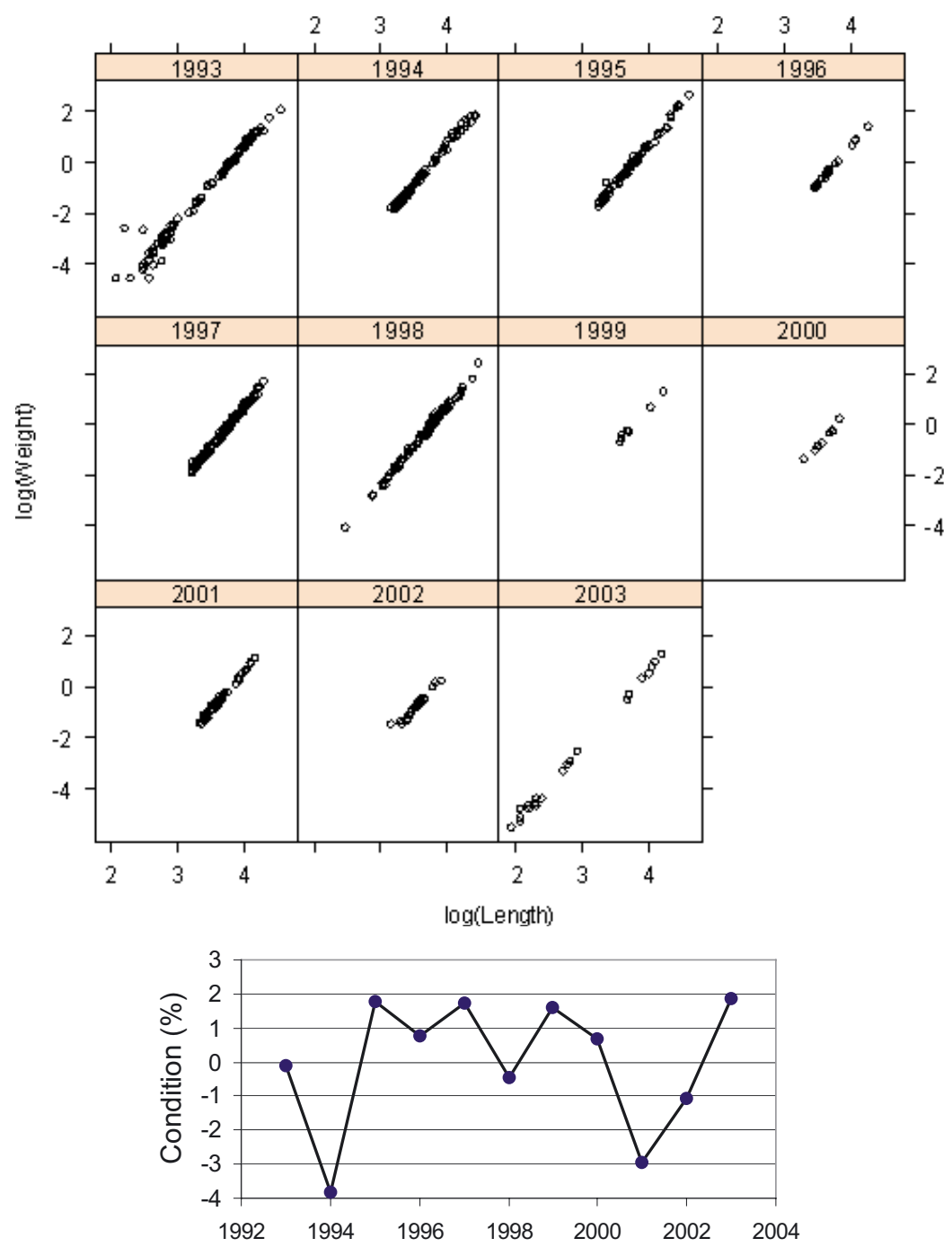

Fig. 6. Example of condition indices, $C$, for cod caught in the Irish Sea beam trawl survey, quarter 3, 1993-2003; (a) Log weight plotted against log length from length-stratified samples collected in the years shown; (b) Re-scaled annual intercepts after exponentiation and transformation to percentage changes relative to the mean. Data supplied by Cefas.

to season, for example after a winter fast, and over the reproductive cycle especially for species with a capital spawning strategy (Stearns 1992), see also Lambert et al. (2003). An ICES study group (Anonymous 2003) recommended that condition data should be routinely collected from surveys because condition influences recruitment, adult mortality, growth, fecundity, maturation, etc. Low condition implies reduced incomes for fishers because they will not attain high prices for the fish they catch.

\section{Sensitivity}

$C$ is not thought to be as sensitive to the physiological status of fish as physiological indicators such as liver weight or lipid content which have direct relevance to energy usage, reproduction, and so on (Anonymous 2003; Lambert and Dutil 1997; Shulman and Love 1999). Fluctuation in condition may be buffered by the reciprocal increase in tissue water content (Rijnsdorp 1990). Changes of condition may reflect seasonal or annual factors rather than a long-term, general decline in the condition of the stock.

\section{Reference points}

There seems to be little reason to set a reference point for condition since it could be affected positively and negatively by both fishing and environmental factors.

\section{Example}

Cod taken as an incidental catch of the quarter 3 Irish Sea beam trawl survey operated by Cefas, Lowestoft are used to illustrate condition, $C$. The data are from length stratified samples. Figure 6a shows natural logarithm of weight of individual cod plotted against $\log$ (length) for each year between 1993 and 2003. The log-log relationship is evidently linear. A linear model was fitted and the annual intercepts representing $\log C$ were transformed to a percentage scale $100(C-$ mean $C) /$ mean $C$ and plotted (Fig. 6b). It can be seen 
that the condition of the cod changed by only a few percent from year to year. There does not appear to be a trend in this time series.

\subsection{Reproductive indicators}

Indicators of reproductive capacity have the potential for assessing the future sustainability of a stock. One, the spawning stock biomass ( $S S B$ ), has been used by European stock assessment working groups for many years. Here we consider three other options that could add considerable detail to the information provided by $S S B$.

All reproductive indicators are highly dependent on the timing of the survey relative to the annual breeding cycle. Variability of timing in relation to the biological year will be displayed as year-to-year noise which may mask the effects of other factors on the indicator. The long-term smoothed levels are likely, nevertheless, to be useful for assessing the sustainability of the stock.

\subsubsection{Spawning stock in number (SSN)}

SSN is the mean catch in number of mature fish per unit of effort during a survey. It indicates the relative abundance of fish with potential to breed.

\section{Estimation}

For trawl surveys, $S S N$ is derived in the same way as the usual survey abundance index but with numbers-mature at each fishing station substituted for numbers. Accurate assessment of maturity is crucial (Kjesbu et al. 2003; Murua et al. 2003) particularly as the proportion mature is likely to be most hard to estimate accurately for the most numerous age classes just coming into maturity; see also http://www.ices. $\mathrm{dk} /$ datacentre/datras/NSIBTSmanualRevVIIdraft.pdf. Careful standardisation of the maturity assessments across years and across survey crews is important to avoid step changes in time or space purely as a result of inconsistent technique. Objective histological methods can be helpful for quality control of maturity assessments based on external morphology. They can also be useful on summer surveys for estimating maturity of species that spawn in winter or spring (Ramsay and Witthames 1996). Geographic variation of maturity stages from north to south is to be expected within a survey region. A problem with some long running international surveys is that different maturity staging systems, e.g. with different numbers of stages, were in use at different times. Mapping one into the other may only be possible by modelling similar to that used in the example for length at maturity, $L a M$, below. The aim would be to find intercalibration constants so as to achieve continuity of maturity assessments between overlapping or consecutive periods when the different staging systems were in use.

\section{Interpretability}

SSN is likely to be informative about the sustainability of a stock but only if treated as supportive for other indicators such as spawning stock biomass ( $S S B)$ and the age structure $(N a A)$ of spawners since large, old fish may be more successful at spawning than young fish. SSN will be most closely related to numbers of the younger age classes that are mature since their abundance will usually be much higher than that of larger, older fish, depending on rates of total mortality, and annual recruitments. Stocks subject to high $F$ or $M$ generally show high proportions of first-time spawners.

Changes in $S S N$ can be caused by fishing but also by natural events such as lack of food, the consequence of which can be delayed or skipped spawning (Anonymous 2003, Sect. 4.4.1). Age at maturity may change due to evolutionary selection pressures exerted by fishing (Law 2000) and the response may be phenotypic (can recover rapidly) or genetic (likely to recover slowly). Reaction norms (Barot et al. 2004; Heino et al. 2002) have been used to disentangle phenotypic from genetic effects.

\section{Sensitivity}

SSN indices will, at least partly, reflect changes in the age composition and reproductive potential of a stock over its geographic domain and over time but precision will mainly depend on the precision of abundance indices and on the success with which the techniques of maturity staging are standardised.

\section{Reference points}

A reference point or target is not suggested partly because abundances tend to be very variable, and partly because breeding success probably does not depend solely on $S S N$.

\section{Example}

Mean SSN, and mean total numbers mature and immature (open diamonds and dotted lines), for sole and plaice (the latter with males and females separately) caught by the Cefas SW beam trawl survey between 1993 and 2001 are shown (Fig. 7). A consistent maturity staging system was in use during this period. Mean SSN and numbers were estimated as CPUEs over stations and standardised per hour and per metre of beam length. Proportions mature were estimated independently in each year from approximately 200 to 400 fish examined during each survey. The variability of $S S N /$ total numbers is reasonably constant for sole, in particular at the beginning and end of the series, for 1993 and 2001 respectively. This appears to be linked with the relatively similar length frequency distributions for sole in these years (Fig. 3). Plaice, both male and female, showed more variability of $S S N /$ total numbers. The lower $S S N$ in 2001 appears to be linked with the large proportion of juvenile fish in that year (Fig. 3). Data were supplied by Cefas Lowestoft, UK.

\subsubsection{Gonadosomatic index (GSI)}

\section{Introduction}

The gonadosomatic index $(G S I)$ is the ratio of gonad weight to body weight or to gonad weight/length ${ }^{3}$. It can indicate nutritional status and reproductive fitness. 

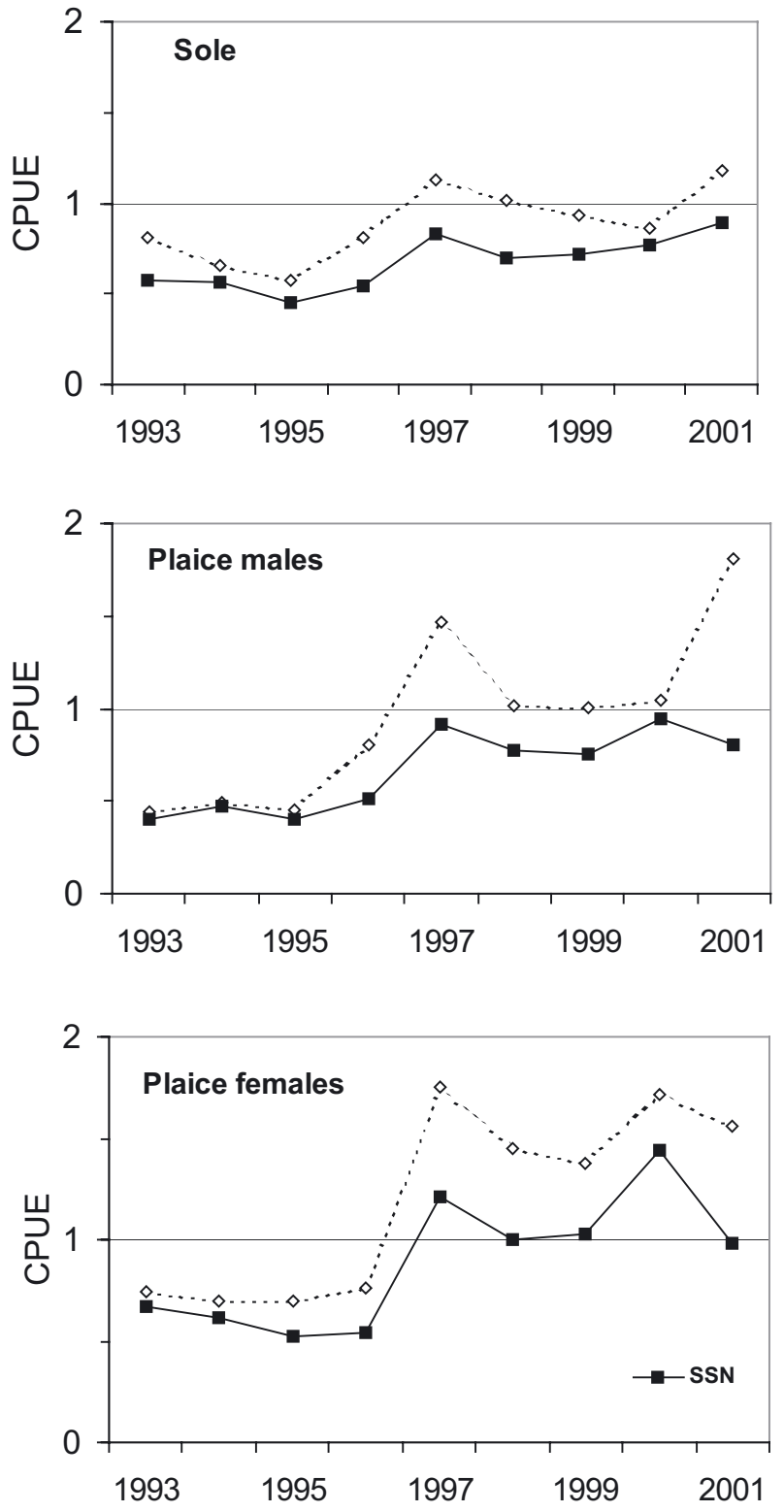

Fig. 7. Example of mean spawning stock numbers, SSN (solid squares and lines), and, for comparison, mean total numbers mature and immature (open diamonds and dotted lines), both as CPUE (numbers $\mathrm{h}^{-1}(\text { beam m})^{-1}$ ), for sole (unsexed) and plaice (sexed) caught by the English SW beam trawl survey, 1993-2001. Means were estimated over stations. Proportions mature were means over approximately 200 to 400 fish examined in each year. Data supplied by Cefas.

\section{Estimation}

Surveys intended to estimate GSI should preferably be timed to coincide with the onset of spawning, or, if that is not possible, to avoid the post-spawning period. A sample of fish from every fishing station should be measured individually for length, body weight, and gonad weight. Stratification by depth bands may be helpful for estimation if GSI is related to depth, as it is for some species (Rijnsdorp 1989). A cut-off length for exclusion of immature individuals would save much pointless dissection work on deck.
Weighing gonads requires that they be removed from the fish and weighed on motion compensated balances. For small fish such as anchovy or sprat, accuracy down to $0.1 \mathrm{~g}$ is desirable. A major advantage of GSI over maturity indices is that it does not require accurate maturity staging. It is therefore less subject to operator bias and requires less training and quality control through inter-calibration, cf. SSN. GSI can suffer from various statistical biases, see García-Berthou and Moreno-Amich (1993) and comments under condition, $C$.

\section{Interpretability}

GSI depends on fish size and is low for immature and recently spawned individuals. It increases rapidly towards the start of the spawning season and is usually highest just prior to ovulation when the first batch of eggs is ready for spawning. GSI may also increase slightly prior to spawning because of loss of non-gonadal weight through aggression with conspecifics or because of spawning migrations. GSI is likely to vary with latitude because of temperature effects on maturation. A low GSI in fish of mature age at the start of the spawning season may imply skipped spawning (Rideout et al. 2005), suggesting too much competition for available food, as well as low reproductive success in the coming spawning season, either through lack of fertile adults or through reduced egg production.

\section{Sensitivity}

The GSI is very sensitive to maturity stage and the timing of the spawning cycle. Hence year-to-year sampling noise may be high and may mask the effects of other factors such as food availability.

\section{Reference points}

Study of historic data might reveal when a low GSI signals poor reproductive capabilities of a stock, provided that signal and noise can be adequately distinguished in the study.

\section{Example}

A time series of GSI from a fish survey was not available. Instead, results from a seasonal research study (Ramsay and Witthames 1996) in all months between July 1993 and August 1994 are illustrated in figure 8. Female sole of 3 year classes, 1989, 1990, and 1991, were sampled from commercial catches taken in the Channel, division VIId, and dissected to determine gonad weights and body length. Body weights were not measured so GSI was estimated as gonad weight/length ${ }^{3}$. It can be seen that all fish displayed a low GSI in late summer and early winter. For most fish, the GSI increased substantially in the first half of 1994 following a typical seasonal pattern, and the increase was larger for the older year classes. The importance of monitoring GSI at a fixed time of year is evident.

\subsubsection{Length and age at maturity (LaM50, AaM50)}

LaM50 and AaM50 are the length or age, respectively, at which $50 \%$ of the individuals in a fish stock have reached 


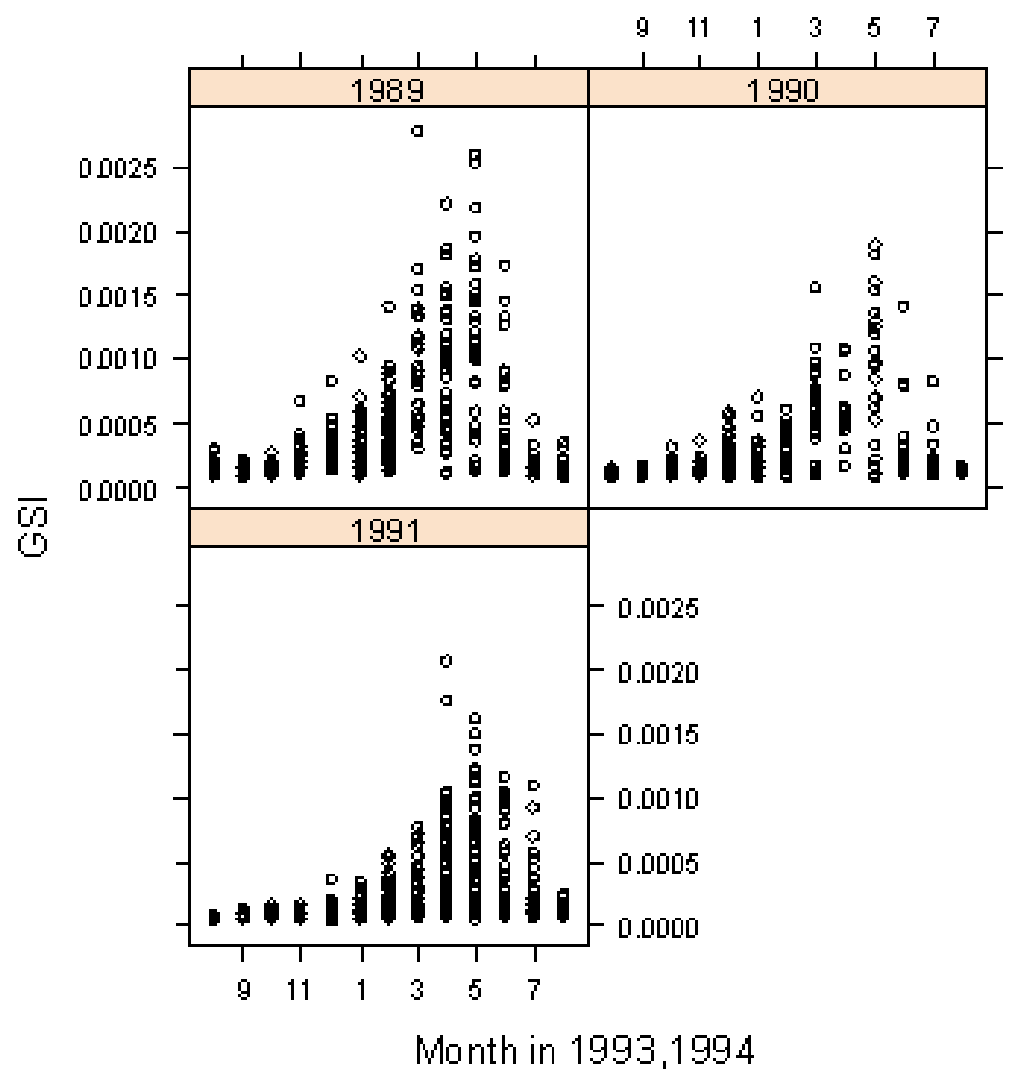

Fig. 8. Example of gonadosomatic index, GSI, for female sole of 3 year classes caught by commercial fishing vessels operating in the Channel (ICES VIId) in different months ( 1 = January, 11 = November) between August 1993 to August 1994. Data supplied by Cefas.

reproductive maturity. LaM50 and AaM50 can indicate reproductive capability, spawning stock biomass, and nutritional status.

\section{Estimation}

Since maturity staging requires that fish be opened and the gonads be examined carefully, observations on deck are timeconsuming. The observed percentage of fish mature at each length is plotted against length for each annual survey. Fitting a logistic or other model is likely to be the best way to estimate the LaM50 for large amounts of data. If otoliths are removed at the same time as gonads are examined, the AaM50 can be estimated similarly from a plot over age.

\section{Interpretability}

AaM50 has been found to decrease under the effect of fishing (Rochet et al. 2000; Trippel 1995, 2003). Young fish of several commercial species are thought to produce smaller, less viable eggs than old fish, and their spawning periods tend to be shorter so that there is less chance for the planktonic larvae to find satisfactory conditions for development (Trippel 1995, 2003). If individual growth were unaffected by the impact of fishing, LaM50 would be expected to decrease in a similar manner to AaM50. LaM50 and AaM50 may both vary with location, particularly with latitude if accompanied by changing temperatures.
Variations of LaM50 and AaM50 may be a result of the evolutionary selection pressures exerted by commercial fishing (Heino 1998; Law 2000; Stokes and Law 2000). Reaction norms (Barot et al. 2004; Heino et al. 2002) are used to describe the phenotypic range of LaM50 and AaM50, and to identify evolutionary selection of alleles favouring early maturation. They may already be in the genetic structure of the population, or they may be introduced by genetic drift and/or mutation .

\section{Sensitivity}

Problems with achieving consistent maturity staging from year to year when using only external morphology may significantly reduce the sensitivity of LaM50 and AaM50 to fishery and environmental factors. Better sensitivity could be expected if histological examinations are carried out for each fish but this is obviously much more time-consuming. LaM50 and AaM50 are both sensitive to growth and mortality and thus might respond phenotypically to decreased density and increased mortality in exploited populations (e.g. Reznick 1993).

\section{Reference points}

Values from a previous stable period when fishing pressures are thought to have been less intense may be useful. 
Table 2. North Sea cod maturity: regression statistics estimated for preparation of Figure 9. A logistic model was fitted to maturity data from 7 countries taking part in the quarter 1 International Bottom Trawl Survey, 1991 to 2004. Raw data supplied by ICES secretariat. LaM50 = length at 50\% maturity.

\begin{tabular}{lccc}
\hline $\begin{array}{l}\text { Explanatory } \\
\text { variable or } \\
\text { factor }\end{array}$ & $\begin{array}{c}\text { Estimate and } \\
\text { significance: } \\
\boldsymbol{p}<\mathbf{0 . 0 1}\end{array}$ & $\begin{array}{c}\text { Std. Error } \\
+-\end{array}$ & $\begin{array}{c}\text { Length } \\
\text { correction to } \\
\text { LaM50(cm) }\end{array}$ \\
\hline Length & $0.1204 * *$ & 0.0013 & Not applicable \\
England & -0.1192 & 0.1840 & 1.0 \\
France & $-0.5244 * *$ & 0.0710 & 4.4 \\
German & & & \\
Federal Rep. & $0.3629 * *$ & 0.0691 & -3.0 \\
Netherlands & $0.2101 * *$ & 0.0760 & -1.7 \\
Norway & $-2.6375 * *$ & 0.0877 & 21.9 \\
Scotland & $0.3881 * *$ & 0.0690 & -3.2 \\
Sweden & $0.6967 * *$ & 0.0636 & -5.8 \\
Male sex & $0.5180 * *$ & 0.0301 & -4.3 \\
\hline
\end{tabular}

\section{Example}

Maturity staging data for cod obtained by the quarter 1 International Bottom Trawl Survey (IBTS) of the North Sea are used to illustrate length at 50\% maturity, LaM50. To ensure a consistent series, only those results with 4 numbered maturity stages (Anonymous 2009) were used. This restricted the data set to the surveys from 1991 to 2004 by 7 collaborating European countries (Table 2). Stage 1 fish were classified as immature, and stages 2, 3, and 4 as mature. A generalized linear model (GLM) was used to fit numbers of fish mature and immature as linear functions of length, year, country, and sex, the last three as factors, using a binomial link function. Table 2 shows all of the estimated parameters except for the 14 year parameters (to save space), and the corrections that each gave to the estimated LaM50 $=-($ year + sex + country $) /$ length coefficient. This formula is derived from-intercept/slope which is the general formula for the $50 \%$ point of a logistic curve. It can be seen that males are estimated to mature on average at lengths $4.3 \mathrm{~cm}$ less than females. Differences between countries are probably at least partly explained by the different latitudes of the national surveyed areas within the North Sea; e.g. Norway is the most northerly. The estimated LaM50s for female cod is calculated by omitting sex and country in the formula for summarising purposes (Fig. 9). A clear decline of around $15 \mathrm{~cm}$ is evident from 1991 to 1999 when there appears to be a levelling off.

\section{Case study: North Sea cod}

A selection of the foregoing biological indicators together with an analysis of year-class curves (Cotter et al. 2007) to estimate $Z$ and recruitments is now applied to a single stock, the North Sea cod, as observed with a single trawl survey, the EGFS, to illustrate how a survey-only assessment might be approached. All results presented here are corrected for the change of trawl and towing time in 1992 (cf. $r$, above).

Declining log total abundance of cod relative to other roundfish species since the early 1980s is shown (Fig. 1), and

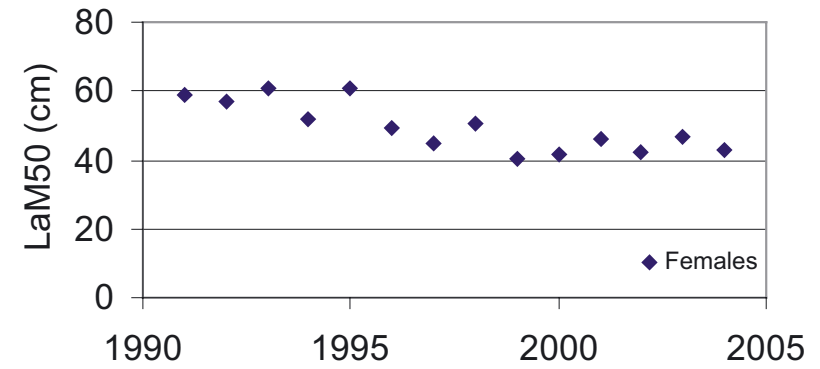

Fig. 9. Example of length at 50\% maturity, LaM50, for female cod caught in the North Sea by 7 countries taking part in the quarter 1 International Bottom Trawl Survey, 1991 to 2004, as estimated using a logistic model fitted to data for proportions mature-at-length. Raw data supplied by ICES secretariat.

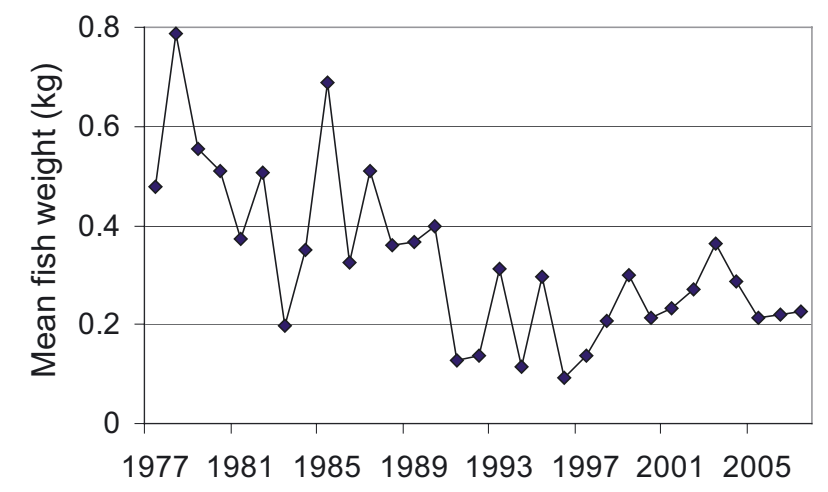

Fig. 10. North Sea cod case study, $3^{\text {rd }}$ quarter EGFS: average live weight of individual fish caught, 1977 to 2007. Data supplied by Cefas.

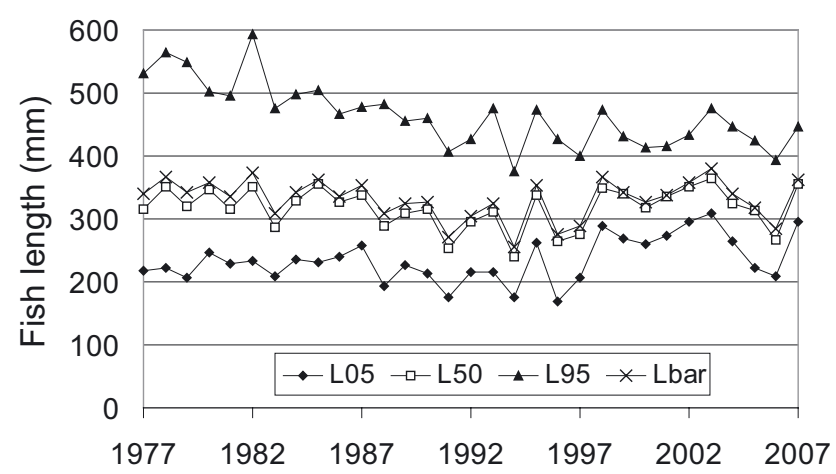

Fig. 11. North Sea cod case study, $3^{\text {rd }}$ quarter EGFS: length quantiles, $L 05, L 50$, and L95, and mean length, Lbar computed "over stations" (Cotter 2009b), 1977 to 2007. Data supplied by Cefas.

declining WPUE (Fig. 5). Average weight per fish caught declined as well (Fig. 10). This information is of immediate relevance to the fishing industry besides being consistent with the expected effects of prolonged fishing pressure. Further evidence for the latter is the reducing LaM50 of female North Sea cod since the early 1990s, for which IBTS quarter 1 results are shown in Figure 9. The effect suggests that breeding by small individuals was becoming more important, presumably because they have experienced less cumulative fishing pressure than large individuals.

Figure 11 shows the L05, L50, L95, and Lbar computed over stations for cod. They may be compared with those over 


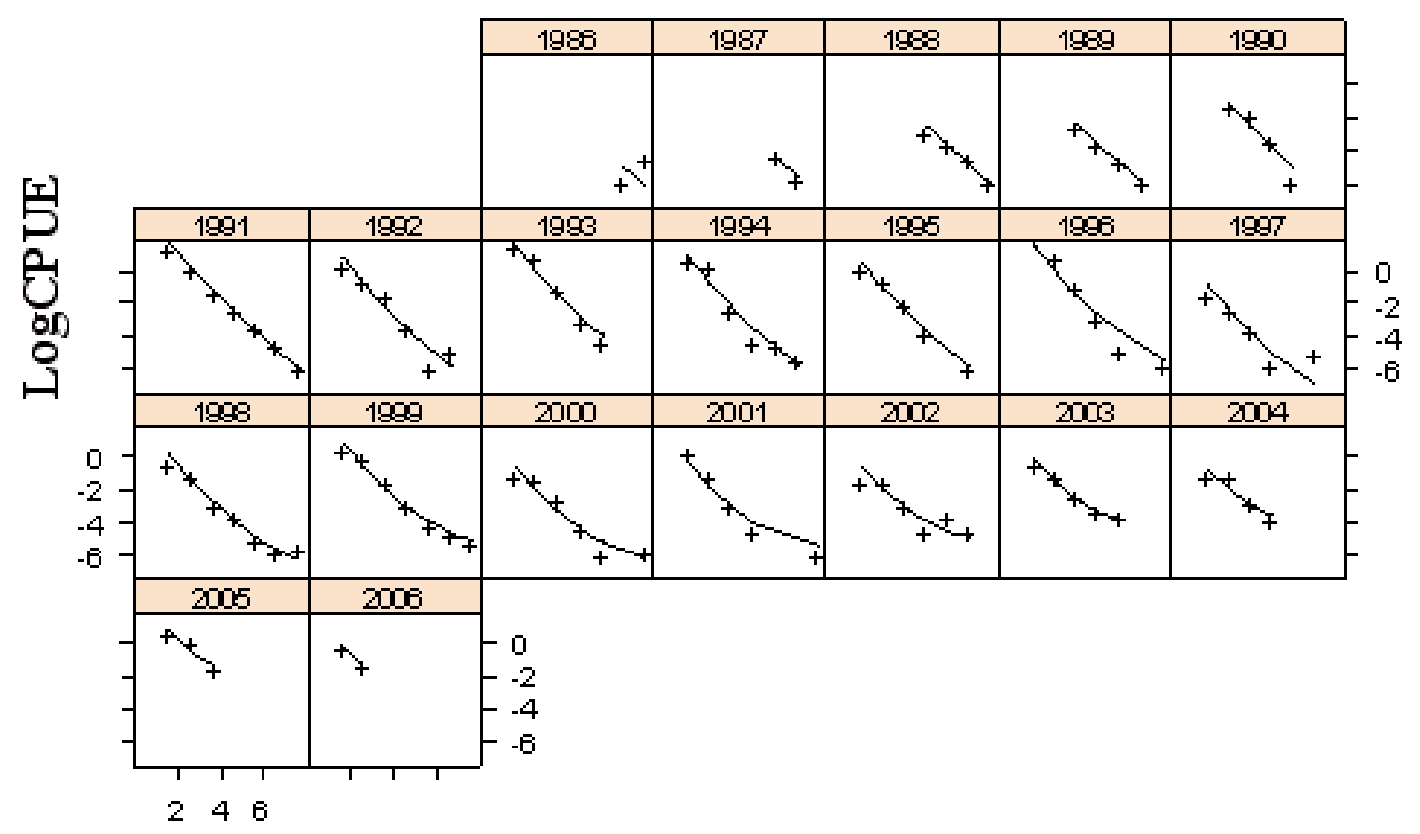

Age

Fig. 12. North Sea cod case study, $3^{\text {rd }}$ quarter EGFS: observed $\log$ CPUE indices (numbers $\mathrm{h}^{-1}$ ) fitted by least squares with (in $\mathrm{R}$ notation): LnCPUE $\sim$ Fleet + Yclass + Selectivity + Age + Age.year + Age.year ${ }^{2}+$ Age.year ${ }^{3}-1$. Panel strips show year class. Graphic output from YCC program (Cotter et al. 2007). Data supplied by Cefas.

stations for North Sea haddock, also obtained on the EGFS (Fig. 4b). The $L 95$ for cod reduced gradually while that for haddock remained at much the same level from 1980. Trends for the other length statistics are not strikingly different between the two species. Both display higher L05, L50, and Lbar in the last part of the series, from 1998 for cod, and from 2001 for haddock. Investigating the possible influences of biological and fishery management changes in recent years would be a feasible task for a stock working group but will not be attempted here.

Year-class curves were fitted to abundance indices-at-age (1 to 7 years old) produced from the EGFS. The time series was divided into two "fleets", pre- and post-GOV. The model chosen on the basis of lowest mean square log prediction error, mean prediction bias nearest 1 , lowest AIC and most evenly distributed residuals and prediction errors around zero was, in R notation (Venables and Ripley 2002):

$$
\begin{aligned}
\text { LnCPUE } \sim & \text { Fleet }+ \text { Yclass }+ \text { Selectivity }+ \text { Age }+ \text { Age.year } \\
& + \text { Age.year }{ }^{2}+\text { Age.year }{ }^{3}-1 .
\end{aligned}
$$

This model satisfactorily allowed for curvature in the decline of the log CPUE of each year class, as well as apparent changes in $Z$ over the period. Year-class curves from 1992 are illustrated (Fig. 12). The upward bend with age contrasts with the straight lines seen for North Sea plaice in Figure 2 and suggests that either old cod (i) are more catchable by the survey, or (ii) are less catchable by the commercial fishing fleet or, (iii) have a lower natural mortality rate than young cod. This effect of the fitted selectivity parameter is also seen as differing mortality rates with age (Fig. 13) where $Z$ is shown as a negative value (as estimated by the regression method). The

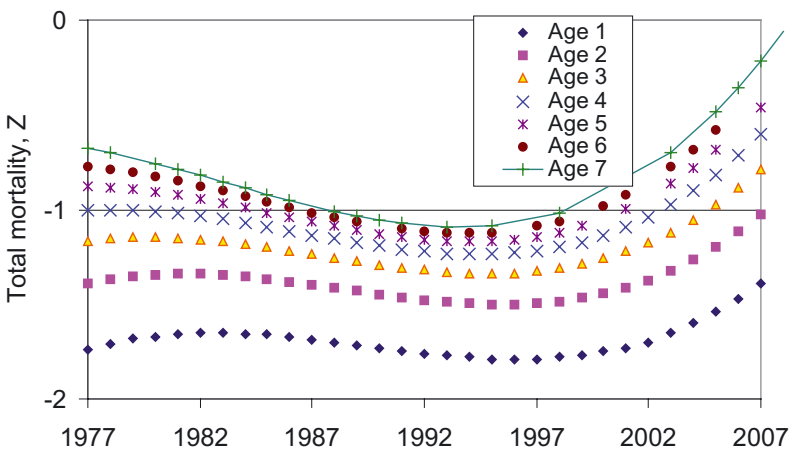

Fig. 13. North Sea cod case study, $3^{\text {rd }}$ quarter EGFS: estimated total mortality, $Z$ (shown as negative values), for ages 1 to 7 between 1977 and 2007 using the YCC model given for Figure 12.

pattern of variation over time is permitted by the polynomial terms in the model and indicates that mortality rates decreased from the late 1990s. This is consistent with management measures to reduce fishing pressure on the cod taken since around 1998 (Sect. 2.1.2, Anonymous 2007b).

Log recruitment indices (age 0 ) estimated by the model are shown (Fig. 14). The trend downwards matches those for log total abundance (negative $r$ ) and WPUE in Figures 1 and 5 quite well, suggesting that a relationship may exist. Figure 15 shows the log recruit index for year classes $Y+1$ plotted over $\log$ WPUE for year $Y$. Linear regression found an $R^{2}$ value of 0.60 . Repeating the analysis with year classes $Y+2$ and $Y+3$ found $R^{2}$ values of 0.50 , and 0.43 respectively. These results suggest that, over that period, recruitment could have 


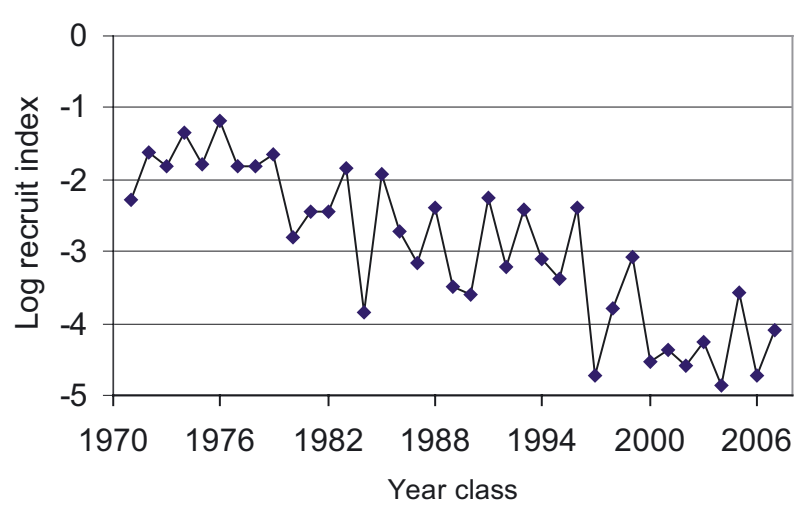

Fig. 14. North Sea cod case study, $3^{\text {rd }}$ quarter EGFS: estimated log recruitment indices for year classes 1971 to 2007 using the YCC model given for Figure 12.

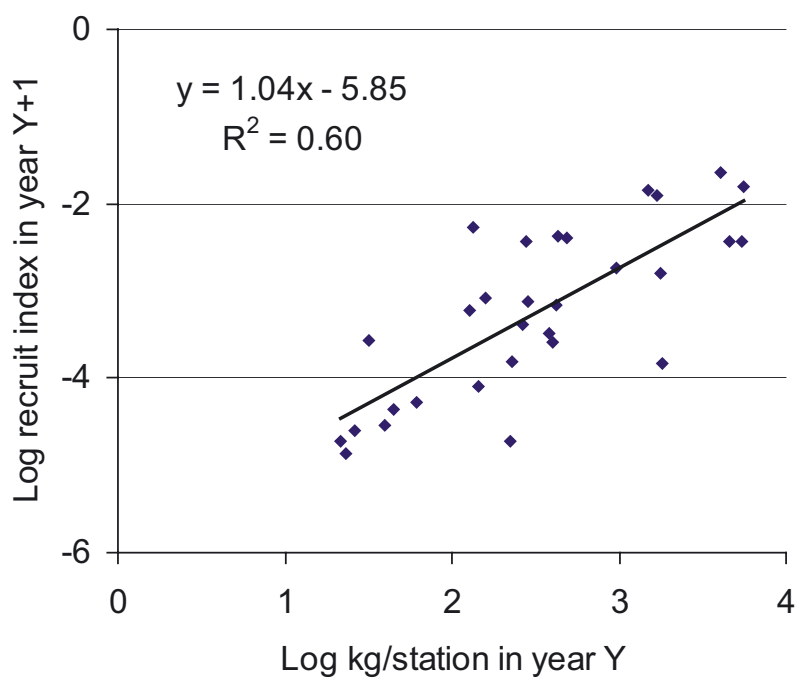

Fig. 15. North Sea cod case study, $3^{\text {rd }}$ quarter EGFS: Log-linear stock recruitment relationship estimated by least squares from WPUE (Fig. 6) and recruitment (Fig. 14) in the following year.

been predicted approximately from stock biomass some way into the future using only the results from one survey. The explanation for this potentially useful result is unclear, especially as WPUE was used instead of spawner WPUE, equivalent to spawning stock biomass. Also, the same model only found an $R^{2}$ of 0.002 for haddock recruits using results from the same survey. Since small fish may not breed as successfully as large fish, the decline in recruitment could also be linked with the declining weights of individual fish (Fig. 10), and/or with the declining LaM50 (Fig. 9). For comparison, ICES previously published a stock-recruitment relationship (on linear scales) for this stock in the report of the 2004 working group (Anonymous 2005).

In summary, this assessment of the North Sea cod clearly supports the ICES view that the stock has diminished substantially in recent decades (Anonymous 2007b). Falling recruitment success may be linked to the reduced sizes of fish in the stock. Future recovery is likely judging from reducing $Z$ in recent years. The implications for fishers of reduced stock levels are shown by the reduced weight of the catch and size range of the fish caught. The several indicators illustrated offer considerable opportunities for improving the biological understanding, and thus the management of this stock. A general discussion of how to manage a stock using only the information from fisheries surveys is given by Cotter et al. (2009).

\section{Conclusion}

The indicators presented here cover most biological aspects of a fish population of relevance to fisheries biologists. The indicators could all be varied in numerous ways so as to suit the available scientific resources and the type of species being monitored in the most appropriate way. Given adequate resources, and given that trends in the chosen indicators would be interpretable, monitoring of a broad range of biological features is likely to be the best policy for understanding what is happening to a stock in response to fishing or other factors (Trenkel et al. 2007). On the other hand, monitoring many indicators "just in case" is probably not a good policy because it can lead to unnoticed redundancy, particularly if high sampling variance masks synchronicity among the indicator series. Redundancy wastes scientific effort and can be misleading if

- Sampling error is treated as signal in a search for different information among all the different indicators. Statistically separating sampling error from signal is difficult when, as is usually the case, the likely form of the signal is unknown.

- The weight of evidence inferred from a set of indicator series is intuitively decided from the number of them showing a common signal without considering whether they are all connected in some way to a single, possibly irrelevant, common factor.

- Redundant time series are "dredged" for information without regard for the dangers of a posteriori reasoning.

Multivariate techniques can help to find common signals in correlated indicators (Petitgas 2009).

Another important issue on some surveys is whether procedures for sampling and observing individual fish are adequate for monitoring biological indicators, especially when that task is a new or subsidiary priority. Survey crews may need extra briefing to ensure that fish in the required size categories are sampled objectively and without bias. The usual ideal is for each individual fish in a catch to have an equal probability of selection for observation though, in practice, cruise leaders may have to settle for, for example, shuffling the contents of fish baskets, then picking one basket at random for processing. Catch samples should also be spread throughout the surveyed area or stratum of interest, rather than being taken opportunistically from a few large catches that are sufficient to fill the sampling quota. Last but not least, the measurements needed for the indicators must be made with adequate care as well as being standardised from place to place and year to year of the survey. This implies training of different survey crews to common standards in what, for them, may be new techniques. Written versions of standard operating procedures should exist from the start so that there is no need to worry whether procedures varied during the course of a time series, possibly contributing to any observed trend over the years. 
Acknowledgements. This paper benefited from the experience and advice of other participants in the FISBOAT project, notably Verena Trenkel and Marie-Joëlle Rochet, although none of these people is responsible for the final text. The study was carried out with financial support from the European Union, project FISBOAT, contract FP6 No. 502572, as well as from national governments of participating groups. Views expressed here should not be construed as official policy of any of these bodies.

\section{References}

Anderson C.N.K., Hsieh C.-H., Sandin S.A., Hewitt R., Hollowed A., Beddington J., May R.M., Sugihara G., 2008, Why fishing magnifies fluctuations in fish abundance. Nature 452, 835-839.

Anderson R.O., Neumann R.M., 1996, Length, weight, and associated structural indices. In: Murphy B.R., Willis D.W. (Eds.) Fisheries Techniques, Bethesda, Maryland, American Fisheries Society, pp. 447-482.

Anonymous, 2003, Report of the study group on growth, maturity and condition in stock projections. International Council for the Exploration of the Sea, Copenhagen, ICES CM 2003/D:01 Ref. ACFM, C, G, H, WGMG.

Anonymous, 2004, Report of the workshop on survey design and data analysis (WKSAD). International Council for the Exploration of the Sea, Copenhagen, ICES CM 2004/B:07, Ref. D.G. http:// www.ices.dk/reports/FTC/2004/WKSAD04.pdf

Anonymous, 2005, Report on the assessment of demersal stocks in the North Sea and Skagerrak. International Council for the Exploration of the Sea, Copenhagen, ICES CM 2005/ACFM:07. http://www.ices.dk/iceswork/wgdetailacfm.asp?wg=WGNSSK

Anonymous, 2006, Report of the study group on survey trawl standardisation (SGSTS). International Council for the Exploration of the Sea, ICES CM 2006/FTC:05, 67 pp. http://www.ices.dk/ reports/FTC/2005/SGSTS05.pdf

Anonymous, 2007a, Development of EcoQO on changes in the proportion of large fish and evaluation of size-based indicators. International Council for the Exploration of the Sea, Copenhagen, ICES ACE Report 2007.

Anonymous, 2007b, Report of the working group on the assessment of demersal stocks in the North Sea and Skagerrak - combined spring and autumn. International Council for the Exploration of the Sea, Copenhagen, ICES CM 2007\ACFM:18 and 30.

Anonymous, 2009, Manual for the International Bottom Trawl Surveys. Rev. VII. International Council for the Exploration of the Sea, Copenhagen. http://www.ices.dk/datacentre/datras/ NSIBTSmanualRevVIIdraft.pdf

Apostolaki P., Hillary R., 2009, Harvest control rules in the context of fishery-independent management of fish stocks. Aquat. Living Resour. 22, 217-224.

Ault J.S., Smith S.G., Bohnsack J.A., 2005, Evaluation of average length as an estimator of exploitation status for the Florida coralreef fish community. ICES J. Mar. Sci. 62, 417-423.

Babcock R.C., Kelly S., Shears N.T., Walker J.W., Willis T.J., 1999, Changes in community structure in temperate marine reserves. Mar. Ecol. Prog. Ser. 189, 125-134.

Barot S., Heino M., O’Brien L., Dieckmann U., 2004, Long-term trend in the maturation reaction norm of two cod stocks. Ecol. Applic. 14, 1257-1271.
Beare D., Castro J., Cotter J., van Keeken O., Kell L., Laurec A., Mahé J.C., Moura O., Munch-Petersen S., Nielsen R., Piet G., Simmonds J., Skagen D., Sparre P., 2002, Evaluation of research surveys in relation to management advice (EVARES). Final report. DGXIV Fisheries, European Commission, Brussels FISH/2001/02 - Lot 1.

Bolger T., Connolly P.L., 1989, The selection of suitable indices for the measurement and analysis of fish condition. J. Fish Biol. 34, 171-182.

Caswell H., 2001, Matrix population models. Construction, analysis, and interpretation., Sinauer Associates, Sunderland, Massachusetts.

Chen P., Yuan W., 2006, Demographic analysis based on the growth parameter of sharks. Fish. Res. 78, 374-379.

Cone R.S., 1989, The need to reconsider the use of condition indices in fishery science. Trans. Am. Fish. Soc. 118, 510-514.

Cone R.S., Springer T.A., Murphy B.R., Gutreuter S., Anderson R.O., Miranda L.E., Jackson D.C., 1990, Properties of relative weight and other condition indices. Trans. Am. Fish. Soc. 119, 10481058.

Cotter A.J.R., 1998, Method for estimating variability due to sampling of catches on a trawl survey. Can. J. Fish. Aquat. Sci. 55, 1607-1617.

Cotter A.J.R., 2001, Intercalibration of North Sea International Bottom Trawl Surveys by fitting year-class curves. ICES J. Mar. Sci. 58, 622-632 [Erratum, Ibid. 58:1340].

Cotter J., 2009a, A selection of nonparametric statistical methods for assessing trends in trawl survey indicators as part of an ecosystem approach to fisheries management (EAFM). Aquat. Living Resour. 22, 173-185.

Cotter J., 2009b, Statistical estimation of mean value of fish stock indicators from trawl surveys. Aquat. Living Resour. 22, 127133.

Cotter A.J.R., Mesnil B., Piet G., 2007, Estimating stock parameters from trawl cpue-at-age series using year-class curves. ICES J. Mar. Sci. 64, 234-247.

Cotter J., Petitgas P., Abella A., Apostolaki P., Mesnil B., Politou C.-Y., Rivoirard J., Rochet M.-J., Spedicato M.T., Trenkel V.M., Woillez M., 2009, Towards an ecosystem approach to fisheries management (EAFM) when trawl surveys provide the main source of information. Aquat. Living Resour. 22, 243-254.

Cressie N., 1993, Statistics for spatial data, revised edition., J. Wiley, Inc., New York.

Cury P.M., Christensen V., 2005, Quantitative ecosystem indicators for fisheries management. ICES J. Mar. Sci. 62, 307-310.

Deriso R.B., Parma A.M., 1988, Dynamics of age and size for a stochastic population model. Can. J. Fish. Aquat. Sci. 45, 10541068.

García-Berthou E., Moreno-Amich R., 1993, Multivariate analysis of covariance in morphometric studies of the reproductive cycle. Can. J. Fish. Aquat. Sci. 50, 1394-1399.

Garcia S.M., Staples D.J., 2000, Sustainability reference systems and indicators for responsible marine capture fisheries: a review of concepts and elements for a set of guidelines. Mar. Freshw. Res. $51,385-426$.

Gedamke T., Hoenig J.M., Musick J.A., DuPaul W.D., Gruber S.H., 2007, Using demographic models to determine intrinsic rate of increase and sustainable fishing for elasmobranchs: pitfalls, advances, and applications. N. Am. J. Fish. Manage. 27, 605-618. 
Greenstreet S.P.R., Rogers S.I., 2006, Indicators of the health of the North Sea fish community: identifying reference levels for an ecosystem approach to management. ICES J. Mar. Sci. 63, 573593.

Haedrich R.L., Barnes S.M., 1997, Changes over time of the size structure in an exploited shelf fish community. Fish. Res. 31, 229-239.

Halliday R.G., Mohn R., 2001, Proceedings of the Fisheries Management Studies working group, Canadian Science Advisory Secretariat, Proc. Ser. 2001/08 Appendix 5.

Heessen H.J.L., 1997, The International Bottom Trawl Survey in the North Sea, the Skagerrak and Kattegat. International Council for the Exploration of the Sea., ICES CM 1997/Y:31.

Heino M., 1998, Management of evolving fish stocks. Can. J. Fish. Aquat. Sci. 55, 1971-1982.

Heino M., Deickmann U., Godø O.R., 2002, Measuring probabilistic reaction norms for age and size at maturation. Evolution 56, 669678.

Hewitt D.A., Hoenig J.M., 2005, Comparison of two approaches for estimating natural mortality based on longevity. Fish. Bull. 103, 433-437.

Horst T.J., 1977, Use of the Leslie matrix for assessing environmental impact with an example for a fish population. Trans. Am. Fish. Soc. 106, 253-257.

Jennings S., 2005, Indicators to support an ecosystem approach to fisheries. Fish Fish. 6, 212-232.

Jennings S., 2007, Reporting and advising on the effects of fishing. Fish Fish. 8, 269-276.

Jennings S., Reynolds J.D., Mills S.C., 1998, Life history correlates of responses to fisheries exploitation. Proc. R. Soc. Biol. Sci. B 265, 333-339.

Jennings S., Dulvy N.K., 2005, Reference points and reference directions for size-based indicators of community structure. ICES J. Mar. Sci. 62, 397-404.

Jennings S., Greenstreet S.P.R., Reynolds J.D., 1999, Structural change in an exploited fish community: a consequence of differential fishing effects on species with constrasting life histories. J. Anim. Ecol. 68, 617-627.

Kennedy J., Witthames P.R., Nash R.D.M., 2007, The concept of fecundity regulation in plaice Pleuronectes platessa L. tested on three Irish Sea spawning populations. Can. J. Fish. Aquat. Sci. 64, 587-601.

Kennedy J., Witthames P.R., Nash R.D.M., Fox C.J., 2008, Is fecundity in plaice (Pleuronectes platessa L.) down-regulated in response to reduced food intake during autumn? J. Fish Biol. 72, 78-92.

Kjesbu O.S., Hunter J.R., Witthames P.R., 2003, Report of the working group on modern approaches to assess maturity and fecundity of warm- and cold-water fish and squids. Institute of Marine Research, Bergen, Norway, Fisken og havet 12.

Kot M., 2001, Elements of mathematical ecology. Cambridge University Press, Cambridge, UK.

Kvamme C., Froysa K.G., 2004, Assessing the effects on stocks of selectivity changes in a fishery. Fish. Res. 69, 283-292.

Lambert Y., Dutil J.-D., 1997, Can simple condition indices be used to monitor and quantify seasonal changes in the energy reserves of Atlantic cod (Gadus morhua)? Can. J. Fish. Aquat. Sci. 54 (Suppl. 1), 104-112.
Lambert Y., Yaragina N.A., Kraus G., Marteinsdottir G., Wright P.J., 2003, Using environmental and biological indices as proxies for egg and larval production of marine fish. J. NW Atl. Fish. Sci. 33, $115-159$.

Law R., 2000, Fishing, selection, and phenotypic evolution. ICES J. Mar. Sci. 57, 659-668.

Marchal P., Andersen B., Caillart B., Eigaard O., Guyader O., Hovgaard H., Iriondo A., Le Fur F., Sacchi J., Santurtun M., 2007, Impact of technological creep on fishing effort and fishing mortality, for a selection of European fleets. ICES J. Mar. Sci. 64, 192-209.

Marteinsdottir G., Thorarinsson K., 1998, Improving the stock and recruitment relationship in Icelandic cod (Gadus morhua L.) by including age diversity of spawners. Can. J. Fish. Aquat. Sci. 55, 1372-1377.

Mesnil B., Petitgas P., 2009, Detection of changes in time-series of indicators using CUSUM control charts. Aquat. Living Resour. 22, 187-192.

Murua H., Kraus G., Saborido-Rey F., Witthames P.R., Thorsen A., Junquera S., 2003, Procedures to estimate fecundity of marine fish species in relation to their reproductive strategy. J. NW Atl. Fish. Sci. 33, 33-54.

Petigas P., Poulard J.C., 2009, A multivariate indicator to monitor changes in spatial patterns of age-structured fish populations. Aquat. Living Resour. 22, 165-171.

Petitgas P., 2009, The CUSUM out-of-control table to monitor changes in fish stock status using many indicators. Aquat. Living Resour. 22, 201-206.

Piet G., Jennings S., 2006, Response of potential fish community indicators to fishing. ICES J. Mar. Sci. 62, 214-225.

Pope J.G., 2003, Golden ages or magic moments? Nat. Res. Model. $16,439-464$.

Pope J.G., Rice J.C., Daan N., Jennings S., Gislason H., 2006, Modelling an exploited marine fish community with 15 parameters - results from a simple size-based model. ICES J. Mar. Sci. 63, 1029-1044.

Quinn T.J., Deriso R.B., 1999, Quantitative fish dynamics., Oxford University Press.

Quinn T.J., Szarzi N.J., 1993, Determination of sustained yield in Alaska's recreational fisheries. International symposium on management strategies for exploited fish populations., Alaska sea grant college program, University of Alaska, Fairbanks,

Ramsay K., Witthames P.R., 1996, Using oocyte size to assess seasonal ovarian development in Solea solea (L.). J. Sea Res. 36, 275-283.

Reznick D.N., 1993, Norms of reaction in fishes. In: Stokes T.K., McGlade J.M., Law R. (Eds.) The exploitation of evolving resources., Berlin, Springer-Verlag, pp. 72-90.

Rideout R.M., Rose G.A., 2006, Suppression of reproduction in Atlantic cod. Mar. Ecol. Prog. Ser. 320, 267-277.

Rideout R.M., Rose G.A., Burton M.P.M., 2005, Skipped spawning in female iteroparous fishes. Fish Fish. 6, 50-72.

Rijnsdorp A.D., 1989, Maturation of male and female North Sea plaice (Pleuronectes platessa L.). J. Cons. Int. Explor. Mer 46, 35-51.

Rijnsdorp A.D., 1990, The mechanism of energy allocation over reproduction and somatic growth in female North Sea plaice, Pleuronectes platessa L. Neth. J. Sea Res. 25, 279-290. 
Rochet M.-J., Cornillon P.A., Sabatier R., Pontier D., 2000, Comparative analysis of phylogenetic and fishing effects in life history patterns of Teleost fishes. Oikos 91, 255-270.

Rochet M.-J., Trenkel V.M., 2003, Which community indicators can measure the impact of fishing? A review and proposals. Can. J. Fish. Aquat. Sci. 60, 86-99.

Rochet M.-J., Trenkel V.M., Bellail R., Coppin F., Le Pape O., Mahé J.C., Morin J., Poulard J.C., Schlaich I., Souplet A., Vérin Y., Bertrand J., 2005, Combining indicator trends to assess ongoing changes in exploited fish communities: diagnostic of communities off the coasts of France. ICES J. Mar. Sci. 62, 1647-1664.

Salthaug A., Aanes S., 2003, Catchability and the spatial distribution of fishing vessels. Can. J. Fish. Aquat. Sci. 60, 259-268.

Scott B.E., Marteinsdottir G., Begg G.A., Wright P.J., Kjesbu O.S., 2006, Effects of population size/age structure, condition temporal dynamics of spawning on reproductive output in Atlantic cod (Gadus morhua). Ecol. Model. 191, 383-415.

Shin Y.-J., Cury P.M., 2004, Using an individual-based model of fish assemblages to study the response of size spectra to changes in fishing. Can. J. Fish. Aquat. Sci. 61, 414-431.

Shin Y.-J., Rochet M.-J., Jennings S., Field J.G., Gislason H., 2005, Using size-based indicators to evaluate the ecosystem effects of fishing. ICES J. Mar. Sci., 62, 384-396.

Shulman G.E., Love R.M., 1999, The biochemical ecology of marine fishes. In: Southward A.J., Taylor P.A., Young C.M. (Eds.) Advances in Marine Ecology, Academic Press, London, 36.

Sinclair A.F., 2001, Natural mortality of cod (Gadus morhua) in the southern Gulf of St. Lawrence. ICES J. Mar. Sci. 58, 1-10.

Stearns S.C., 1992, The evolution of life histories., Oxford University Press, Oxford, UK.
Stokes T.K., Law R., 2000, Fishing as an evolutionary force. Mar. Ecol. Prog. Ser., 208, 299-313.

Thoresen A., Marshall C.T., Kjesbu O.S., 2006, Comparison of various potential fecundity models for north-east Arctic cod Gadus morhua L. using oocyte diameter as a standardizing factor. J. Fish. Biol. 69, 1709-1730.

Trenkel V.M., Cotter J., 2009, Choosing survey time series for populations as part of an ecosystem approach to fishery management. Aquat. Living Resour. 22, 121-126.

Trenkel V.M., Rochet M.-J., Mesnil B., 2007, From model-based prescriptive advice to indicator-based interactive advice. ICES J. Mar. Sci. 64, 768-774.

Trippel E.A., 1995, Age at maturity as a stress indicator in fisheries. Bioscience 45, 759-771.

Trippel E.A., Ed. 2003, Reproductive potential of fish populations of the North Atlantic. J. NW Atl. Fish. Sci. Dartmouth, Nova Scotia, Northwest Atlantic Fisheries Organization.

Venables W.N., Ripley B.D., 2002, Modern applied statistics with S. Springer, New York.

Vetter E.F., 1988, Estimation of natural mortality in fish stocks: a review. Fish. Bull. 86, 25-43.

Westrheim S.J., Ricker W.E., 1978, Bias in using an age-length key to estimate age-frequency distributions. J. Fish. Res. Board Can. 35, 184-189.

Woillez M., Rivoirard J., Petitgas P., 2009, Notes on survey-based spatial indicators for monitoring fish populations. Aquat. Living Resour. 22, 155-164.

Wood S.N., 2006, Generalized additive models; an introduction with R., Chapman \& Hall/CRC, Boca Raton. 